\title{
Bonaventura Vulcanius traduttore della Catena in Ioannem
}

\author{
MATteo StEFANi
}

The codex Leiden, Universiteitsbibliotheek, ms. Vulc. 9 contains teaching speeches and Greek-into-Latin translations by Bonaventura Vulcanius (1538-1614). Among these materials, the Latin translation of the first chapters of a Catena in Ioannem is an important source to study Vulcanius as a translator. This paper aims to provide the critical edition of Vulcanius' translation with the Greek text according to the codex Paris, Bibliotheque nationale de France, ms. gr. 209, which is identified as the source of the Greek model used by Vulcanius for his translation. ${ }^{*}$

\section{Il codice Leiden, Universiteitsbibliotheek, ms. Vulc. 9}

Bonaventura De Smet, più noto come Vulcanius (Bruges 1538-Leida 1614), studiò e avviò la sua attività di insegnamento poco dopo la metà del sedicesimo secolo tra Spagna, Svizzera e Germania. Ma gli anni più importanti della sua esistenza si svolsero nei Paesi Bassi, luogo d'origine a cui fece ritorno nel 1577 per diventare prima protagonista della Rivolta contro la dominazione spagnola (fu segretario personale di Philip Marnix, conte di Saint-Aldegonde e longa manus di Guglielmo d'Orange) e poi docente di letteratura greca presso l'Università di Leida di recentissima istituzione. ${ }^{1}$ Tra i manoscritti oggi conservati presso la biblioteca universitaria di Leida e un tempo appartenutigli, quello con segnatura Vulc. $9(\mathbf{V})$ offre una preziosa testimonianza sulla sua attività di insegnamento e sui suoi interessi letterari e teologici.

\footnotetext{
* Questo studio è stato condotto nell'ambito del progetto di ricerca "Per la storia dell'educazione umanistica: quaderni di studenti e maestri di greco e latino tra XV e XVI sec." finanziato dal Dipartimento di Studi Umanistici dell'Università degli Studi di Torino (responsabile scientifico: Luigi Silvano). Ringrazio il prof. Luciano Bossina (Università di Padova) per i preziosi consigli sui commenti patristici ai Vangeli e sull'allestimento dell'edizione, il dott. Francesco Siri (IRHT Paris) per aver controllato e discusso i dettagli codicologici del codice Paris, Bibliothèque nationale de France, ms. gr. 209, e gli anonimi referees per aver arricchito il lavoro con correzioni e suggerimenti fondamentali.

${ }^{1}$ Per un inquadramento biografico più dettagliato si vedano: A. Dewitte, "Bonaventura Vulcanius en Philips Marnix van Sint-Aldegonde 1577-1606", in Album Albert Schouteet (Brugge, 1973), 57-74; A. van der Lem, "Bonaventura Vulcanius, forgeron de la Révolte", in H. Cazes (ed.), Bonaventura Vulcanius, Works and Networks. Bruges 1538-Leiden 1614 (Leiden - Boston, MA, 2010), 215-222, con relative bibliografie.
} 
Il codice, ${ }^{2}$ costituito da 89 carte di formato in folio, risulta da un assemblaggio di fogli sparsi che Vulcanius aveva redatto in momenti diversi della sua carriera e che solo in seguito furono raccolti in un unico volume. Ciò appare chiaro non solo a un primo esame del manoscritto, che evidenzia la variabilità della mise en page e della grafia, ma anche quando si constata l'eterogeneità dei materiali in esso raccolti. Alcuni documenti sono legati all'insegnamento universitario: si tratta di quattro discorsi introduttivi su Omero (due), Esiodo e Senofonte, che furono oggetto di altrettanti corsi tenuti da Vulcanius all'incirca negli anni Ottanta del Cinquecento. A questo primo gruppo si affiancano alcune traduzioni latine di testi greci, inerenti le questioni politiche e dottrinali che interessarono l'autorità papale, lo scisma tra le Chiese d'Oriente e d'Occidente e le questioni trinitarie. Infine, compaiono altri documenti variamente legati alla vita istituzionale dell'Università di Leida. ${ }^{3} \mathrm{La}$ maggior parte di questi materiali è stata recentemente studiata nell'ambito di un progetto di ricerca promosso dall'Università di Torino. ${ }^{4}$

\footnotetext{
${ }^{2}$ Per una descrizione del codice: P.C. Molhuysen, Bibliotheca Universitatis Leidensis. Codices Manuscripti 1. Codices Vulcaniani (Leiden, 1910), 5-6; L. Silvano, "Per la tradizione manoscritta della Disputa tra un ortodosso e un latinofrone sulla processione dello Spirito Santo di Giorgio Moschampar. Con un inedito di Bonaventura Vulcanius", Medioevo Greco 14 (2014), 229-265, a 245; M. Stefani, "I prolegomeni di Bonaventura Vulcanius a Le opere e i giorni di Esiodo", Medioevo greco 18 (2018a), 253-279, a 254255. Una riproduzione del codice è reperibile sul sito della Universiteitsbibliotheek di Leida: http://hdl.handle.net/1887.1/item:361241.

${ }^{3}$ Devo a uno dei referees anonimi la segnalazione di una lettera del 6 settembre 1615 di Daniel Heinsius (1580-1655) a Jacques-Auguste De Thou (1553-1617): in essa il mittente lamenta il pessimo stato in cui le carte di Vulcanius furono lasciate dal proprietario alla sua morte e di come gli eredi le avessero scriteriatamente raggruppate (cf. J.-A. de Thou, Historiae sui temporis, vol. 7 (London, 1733), sez. 9, 37-38). Tuttavia, ritengo che in questo caso il lavoro sia stato svolto con qualche criterio, visto che i materiali, per quanto eterogenei e disordinati, sembrano comunque tutti riferibili a questi tre gruppi tematici principali.

${ }^{4}$ Tra le prolusioni accademiche, quella sull'Iliade sarà discussa in L. Silvano, "Introduire un cours de grec entre Humanisme et Renaissance: les prolusiones d'Ange Politien et Bonaventura Vulcanius", in C. Revest (ed.), Le discours académique en Europe, de la scolastique à l'humanisme. Les pratiques de la rhétorique solennelle à l'Université (XIII ${ }^{\text {- }}$ $X V I I^{e}$ siècle) (Paris, in corso di stampa); quella sull'Odissea si leggerà in L. Silvano, "Contro i detrattori di Omero. Una prolusione inedita di Bonaventura Vulcanius", in F. Ciccolella, V. Prosperi, M. Sarnelli (ed.), Homer Between Two Worlds. The Reception of Homer in the Renaissance, from Byzantium to the West (in corso di stampa); quelle su Esiodo e Senofonte sono pubblicate rispettivamente in Stefani 2018a (come a n. 2) e in M. Stefani, "I prolegomeni di Bonaventura Vulcanius alla Ciropedia di Senofonte", Studi medievali e umanistici 16 (2018b), 207-226 (a questi articoli rimando anche per l'inquadramento generale delle prolusioni entro la produzione di Vulcanius). Il materiale di argomento teologico fu per la gran parte pubblicato da Vulcanius stesso: il testo di Agazia Scolastico uscì nel 1594 e quelli di Nilo Cabasila e Andronico Camatero nel 1595. Su
} 


\section{La traduzione di Vulcanius e l'originale greco della Catena in Ioannem}

Tra i materiali inclusi nel codice, spiccano alcune pagine di commento ai Vangeli che occupano i f. 32r-36v: insieme ai cinque fogli bianchi immediatamente successivi, essi vanno a costituire un unico fascicolo comprendente i f. 32r-41v. A un'analisi più approfondita, si scopre che il testo è composto da una successione di passi desunti da Padri Greci, per la maggior parte di breve estensione, che commentano i primi tredici versetti del Vangelo secondo Giovanni. La menzione di ciascun versetto al centro del foglio e l'anteposizione del nome della fonte al genitivo sul margine di ogni sezione permettono immediatamente di riconoscere la versione latina di una Catena, un commento continuo realizzato mediante estratti da opere esegetiche.

Un primo problema posto dal testo riguarda la paternità della traduzione: il suo carattere di autografo, la presenza di alcune note marginali che riportano passi del greco originale a probabile scopo di confronto, il fatto che la traduzione non compaia altrove sotto altro nome e la nota attività di traduttore svolta da Vulcanius nella sua carriera (testimoniata da altri testi presenti nel medesimo codice) depongono a favore della paternità di Vulcanius per quest'opera.

Più problematica è l'identificazione del testo greco su cui la traduzione di Vulcanius è stata condotta. Infatti, per la loro stessa caratteristica di raccolte di estratti, le Catenae producono delle copie di volta in volta profondamente rielaborate: spostamenti, eliminazioni e aggiunte di citazioni da questo o quell'altro testo sono fatti comuni, che rendono ciascun manoscritto portatore di una versione assai peculiare, le cui affinità con altri testimoni risultano difficilmente individuabili. Da ciò discende anche la travagliata storia editoriale del testo greco: l'edizione di riferimento è ancora quella che si legge in J.A. Cramer (ed.), Catena Graecorum Patrum in Novum Testamentum, vol. 2 (Oxford, 1841), riprodotta anche nel database del Thesaurus Linguae Graecae disponi-

queste edizioni, cf. A. Dewitte, "Bonaventura Vulcanius (1538-1614). A Bibliographic Description of the Editions 1575-1612", Lias 8 (1981), 189-201, a 196-197; T.M. Conley, "Vulcanius as Editor: the Greek Texts", in Cazes 2010 (come a n. 1), 337-350, a 340-342 (si tenga presente che 1'edizione è dedicata agli Ordines provinciarum Belgices confederatorum, gli Stati Generali delle Sette Province Unite, e non di "Catholic Belgium", come invece affermato da Conley). L'unica opera di questa sezione non edita da Vulcanius (a parte la Catena qui presentata) è una traduzione parziale di un'opera di Giorgio Moschampar, che si legge ora in Silvano 2014 (come a n. 2), 251-265. 
bile in rete. ${ }^{5}$ Qui tuttavia compaiono, anche nella sezione riguardante Ioh. 1.1-13, estratti desunti da due soli manoscritti-modello (Paris, Bibliothèque nationale de France, ms. Coislin 23, e Oxford, Bodleian Library, ms. Auct. T.I.4), che non coincidono con il modello che traspare dalla traduzione di Vulcanius. Un significativo passo avanti nell'edizione di queste opere, e quindi un quadro assai più chiaro per la nostra indagine, si deve a J. Reuss e R. Devreesse. Nelle loro edizioni di frammenti inediti di Padri greci desunti dalle Catenae, i due studiosi adottano un approccio più ampio, proponendo di riunire i manoscritti noti in differenti famiglie, ciascuna delle quali portatrice di una versione specifica dell'opera. ${ }^{6}$ In questo modo, le variazioni entro il novero degli autori antologizzati diventano, anziché un problema, il fondamentale indicatore per classificare un manoscritto in una famiglia o nell'altra.

Gli autori che compaiono nella traduzione di Vulcanius sono Ammonio di Alessandria (19 estratti), Basilio di Cesarea (3 estratti), Cirillo di Alessandria (11 estratti), Giovanni Crisostomo (13 estratti, di cui due erroneamente ascritti a Basilio), Origene (3 estratti, di cui uno erroneamente accorpato a un estratto crisostomico) e Teodoro di Mopsuestia (5 estratti, di cui uno erroneamente assegnato a Basilio). ${ }^{7}$ La combinazione di questi specifici autori e il gran numero di prelievi da Ammonio sono caratteristiche tipiche delle Catenae "di tipo F" (secondo la classificazione di Reuss) o "della famiglia di Cordier" (secondo quella di Devreesse). I rappresentanti principali di questa famiglia sono tre codici manoscritti e un'edizione a stampa:

${ }^{5}$ Cf. W.R.S. Lamb, The Catena in Marcum. A Byzantine Anthology of Early Commentary on Mark (Leiden, 2012), 32-58.

${ }^{6}$ R. Devreesse, Essai sur Théodore de Mopsueste (Città del Vaticano, 1948); J. Reuss, Johannes-Kommentare aus der Griechischen Kirke (Berlin, 1966). I tentativi di entrambi furono propiziati da un analogo approccio nel catalogare i manoscritti delle Catenae già proposto in G. Karo, I. Lietzmann, Catenarum Graecarum catalogus (Göttingen, 1902).

${ }^{7}$ Il conteggio considera come due estratti crisostomici tra loro separati i r. 81-89 / 8392 (qui e ovunque, in presenza di doppia numerazione, la prima è riferita al testo greco, la seconda a quello latino): infatti, i r. 81-87 / 83-89 presentano testo originale ad verbum, mentre i r. 87-89 / 89-92 una stringata rielaborazione del seguito. Inoltre, essi sono differenti dal precedente frammento di Teodoro di Mopsuestia (r. 48-81 / 47-83), a cui sono erroneamente legati. Anche l'estratto teodoriano è privo del nome della fonte per le ragioni che saranno esposte infra in questo paragrafo: pertanto anch'esso si presenta congiunto al frammento di Basilio immediatamente precedente (r. 11-48 / 10-47). Nella breve introduzione iniziale sul significato di "Vangelo", un frammento di Origene (r. 6-9/ 5-8 è accorpato a quello di Crisostomo (r. 2-6/1-4). 
${ }^{\circ}$ Bernkastel-Kues, Bibliothek des St. Nikolaus-Hospitals, ms. 18 (XI sec.);

${ }^{\circ}$ Paris, Bibliothèque nationale de France, ms. gr. 209 (XI/XII sec.);

${ }^{\circ}$ Berlin, Staatsbibliothek, ms. Phill. 1420 (copiato nel 1542 a Venezia);

- Catena Patrum Graecorum in Sanctum Ioannem ex antiquissimo Graeco codice manu scripto nunc primum in lucem edita [...] a Balthasare Corderio (edizione uscita ad Anversa nel 1630). ${ }^{8}$

Tra tutti i testimoni appena elencati, per il nostro discorso riveste particolare interesse il codice Paris, Bibliothèque nationale de France, ms. gr. 209 (P), ${ }^{9}$ poiché è l'unico esponente del "tipo F" a mostrare delle coincidenze significative con la traduzione di Vulcanius. Quest'ultima riporta tutte le citazioni della catena così come compa-

${ }^{8}$ Questi e altri codici della Catena in Ioannem si trovano tutti sommariamente elencati in Karo-Lietzmann 1902 (come a n. 6), 589-591; Reuss 1941 (come a n. 6), 210-211, descrive solo i codici di Parigi e di Berlino, ma nell'introduzione (6) definisce l'edizione di Balthasar Cordier (1592-1650) "die beste aller alten Katenendrucke". Il codice di Kues e l'edizione di Cordier vanno analizzati congiuntamente: infatti, nell'epistola prefatoria "Al benevolo lettore", Cordier afferma di aver condotto la sua opera di trascrizione su un antico codice "ex Illustrissimi Cardinalis Cusani bibliotheca": la datazione e la descrizione del ms. 18 di Kues suggeriscono che sia proprio questo il manoscritto alla base del volume del 1630. L'identificazione dell'uno o dell'altra con l'esemplare greco di Vulcanius è impedita da sostanziali differenze nell'ordine delle citazioni, da estratti non collimanti (compresi quelli prefatori) e - nel caso dell'edizione - anche dalla cronologia. Sul codice di Cusano rimando a J. Marx, Verzeichnis der Handschriften-Sammlung des Hospitals zu Cues bei Bernkastel a./ Mosel (Trier, 1905), 13; si noti per inciso che Devreesse 1948 (come a n. 6), 266 n. 6, ritiene erroneamente perduto questo manoscritto a causa delle imperfette informazioni date nella descrizione in Karo-Lietzmann 1902 (come a n. 6), 590: i due studiosi indicano una antica segnatura "G 87" come attuale e dicono di non aver potuto vedere il codice, che appena tre anni dopo era invece a disposizione di Marx per la catalogazione. Occorre escludere dagli interessi di questo studio anche il manoscritto berlinese: si tratta di una copia del codice $\mathbf{P}$, realizzata nel 1542 , quando erano entrambi a Venezia. Nel corso del Cinquecento il codice oggi a Berlino venne prelevato dalla collezione Grimani e portato in Francia da Guillaume Pellicier vescovo di Autun (1490-1567), passando poi nel 1573 al Collegio dei Gesuiti di Clermont a Parigi, dove rimase fino alla dispersione della collezione nel 1764: nella seconda metà del Cinquecento il codice era quindi prima lontano da Parigi e poi nelle salde mani dei Gesuiti, circostanze che lo rendevano sicuramente inaccessibile a Vulcanius. Sul codice cf. W. Studemund, L. Cohn, Verzeichniss der griechischen Handschriften der Königlichen Bibliothek zu Berlin I: Codices ex bibliotheca Meermanniana Phillippici Graeci nunc Berolinenses (Berlin, 1890), 5 nr. 16; Reuss 1941 (come a n. 6), 211; su Guillaume Pellicier e la formazione e dispersione della sua biblioteca cf. A. Diller, H.D. Saffrey, L.G. Westerink, Bibliotheca Graeca manuscripta Cardinalis Dominici Grimani (1461-1523) (Mariano del Friuli, 2003), 32; A. Cataldi Palau, "Les vicissitudes de la collection de manuscrits grecs de Guillaume Pellicier", Scriptorium 40 (1986), 32-53.

${ }^{9}$ Per una sua descrizione cf. Reuss 1941 (come a n. 6), 210-211; una riproduzione del manoscritto è disponibile su Gallica: https://gallica.bnf.fr/ark:/12148/btv1b10721841p.

Humanistica Lovaniensia 68.2 (2019), 317-359 
iono in $\mathbf{P}$; l'ordine è il medesimo, la posizione dei versetti giovannei tra gli estratti patristici è la stessa, con la sola eccezione dell'omissione di un brevissimo frammento di Teodoro di Mopsuestia non tradotto da Vulcanius (r. 309-311). Inoltre, è assente sia in $\mathbf{P}$ sia nella traduzione di Vulcanius il lungo prologo (anch'esso con prelievi da opere patristiche, prevalentemente crisostomiche) che invece compare nel codice cusaniano e nell'edizione di Cordier. Analogamente, Vulcanius si accoda con $\mathbf{P}$ in lezioni che in quest'ultimo divergono dalla fonte e dalla Catena di "tipo F". ${ }^{10}$

Infine, a fugare ogni dubbio, giunge una circostanza peculiare: l'analisi codicologica del codice francese mostra che esso è costruito con una successione di quinioni e ternioni alternati, tranne il primo fascicolo. Poiché il secondo è un ternione, il primo fascicolo doveva essere un quinione, ma oggi si presenta assai malconcio e costituito solo da un bifolio (f. 1 e 2) più un foglio singolo (f. 3 ), denunciando la perdita del primo foglio e dei tre bifoli centrali: ${ }^{11}$ a causa di questo problema, il testo greco ha una lacuna tra i f. $1 \mathrm{v}$ e $2 \mathrm{r}$ (un frammento da Basilio si interrompe e lascia spazio a uno di Teodoro di Mopsuestia, che compare quindi di seguito al precedente, senza soluzione di continuità e privo dell'intestazione e della parte iniziale). Nell'edizione di Cordier, il testo corrispondente alla lacuna occupa circa 14.700 lettere, estensione perfettamente compatibile con quella di tre bifoli in $\mathbf{P}$ (contando le lettere di sei delle carte sopravvissute si ottengono tra le 14.300 e le 15.200 lettere). Nella traduzione di Vulcanius questo difetto viene perpetuato: al r. 47 tra "non potest" e "Et ab Apostolo" non vi è alcuna interruzione.

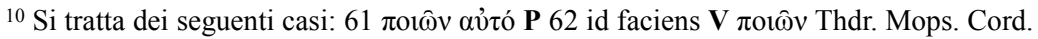

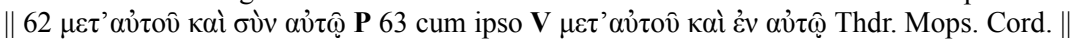

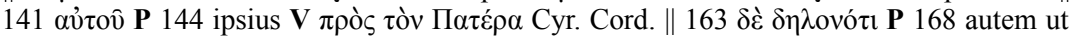

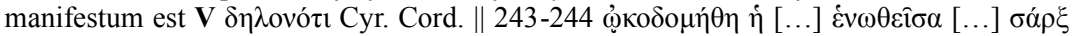

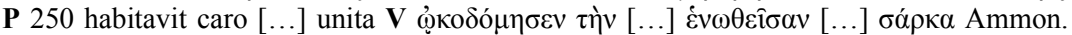

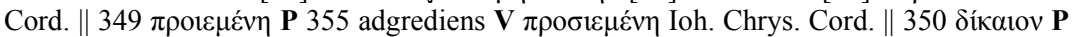

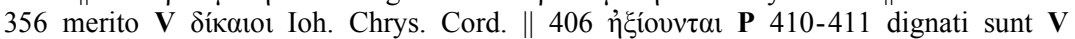

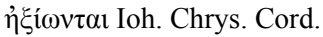

${ }^{11}$ I f. 1 e 2 mostrano un piccolo rinforzo nella parte alta della piegatura, ma continuano a essere uniti nella parte inferiore; la carta mancante a inizio fascicolo potrebbe essere l'attuale f. I nel frattempo staccatosi dal f. 3, ma ciò appare improbabile perché tale carta $\mathrm{e}$ quelle che la precedevano dovevano contenere il prologo mancante.
} 
Tutti questi elementi sono sufficienti a provare che Vulcanius traduceva il testo greco secondo la versione del codice P. Tuttavia, un accesso diretto a questo specifico manoscritto risulta improbabile alla luce delle vicende storiche che lo hanno riguardato. Il manoscritto, dopo essere transitato da Pico della Mirandola (1463-1494) al cardinale veneziano Domenico Grimani (1461-1523) e alla biblioteca del monastero di S. Antonio di Castello, prese la via della Francia, venendo acquistato tra il 1561 e il 1564 dal prelato e diplomatico cattolico Jean Hurault de Boistaillé (†1572). Per vie non del tutto chiare, gran parte della collezione di quest'ultimo pervenne poi a un cugino, il vescovo di Chartres Philippe Hurault de Cheverny ( $† 1620)$, e da questi passò alla raccolte nazionali francesi. ${ }^{12}$ Il manoscritto di Parigi non sembra aver quindi incrociato gli spostamenti di Vulcanius: appare pertanto più probabile che l'umanista abbia utilizzato un suo apografo..$^{13}$ Inoltre, occorre tenere conto di alcune lezioni peculiari di $\mathbf{P}$ che Vulcanius non traduce perché in quei casi si allinea alla fonte e al testo della Catena secondo il codice di Cusano ripreso da Cordier. Se nella maggior parte dei casi si tratta di semplici ritocchi che potevano essere desunti dal contesto, in almeno quattro casi si può sospettare un

12 Per la storia della collezione Grimani: Diller 2003 (come a n. 8), in particolare 3-38, con relativa bibliografia; per quella della collezione di Hurault de Boistaillé: D. Jackson, "The Greek Manuscripts of Jean Hurault de Boistaillé", Studi italiani di Filologia Classica 2 (2004), 209-252, a 209-212 e 251-252; I. Conihout, "Jean et André Hurault: deux frères ambassadeurs à Venise et acquéreurs de livres du cardinal Grimani", Italique. Poésie italienne de la Renaissance 10 (2007), 107-148, a 107-118; K. van Ommen, "Tous mes livres de langues estrangeres. Reconstructing the Legatum Scaligeri in Leyden University Library", Renaissance and Reformation 34.3 (2011), 143-184, a 151-153. Il manoscritto di Parigi è censito tra i manoscritti di Grimani in Diller 2003 (come a n. 8), 133 nr. 155, e in D. Jackson, "A List of Greek Mss of Domenico Grimani”, Scriptorium 62 (2008), 164-169, nr. 155; tra quelli di Hurault de Boistaillé in Jackson 2004, 228-229, nr. 101.

13 Per il quale rimane comunque da trovare un possibile intermediario che l'abbia potuto fornire a Vulcanius. È noto che nel 1593 Joseph Justus Scaliger (1540-1609) ebbe accesso alla collezione di Hurault de Boistaillé, prelevandone alcuni manoscritti oggi conservati nella Universiteitsbibliotheek di Leida: Van Ommen 2011 (come a n. 12), 153157. Non si può escludere quindi che una copia, anche parziale, del manoscritto sia giunta a Vulcanius tramite Scaliger o grazie a uno degli intermediari che permisero a quest'ultimo di acquisire numerosi manoscritti dalla collezione francese: personaggi come De Thou o Franciscus Raphelengius (1539-1597) corrispondevano e collaboravano anche con Vulcanius. Che Scaliger fosse più interessato a manoscritti orientali che a quelli greci è un punto da non sottovalutare e che impedisce di sciogliere le riserve su questo possibile collegamento. Tuttavia, va anche considerata la presenza nella Catena di autori poco noti e reperibili solo per frammenti, come Teodoro di Mopsuestia o Ammonio, elemento in grado di suscitare interesse verso questa raccolta di estratti. 
ricorso diretto alla fonte per emendare il testo greco. ${ }^{14}$ Ciò sembra suggerito anche dai r. 267 / 274-275: qui P legge àvór

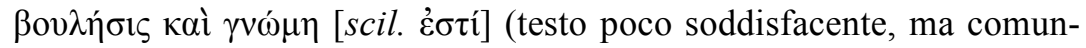

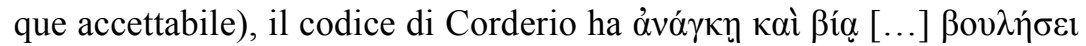

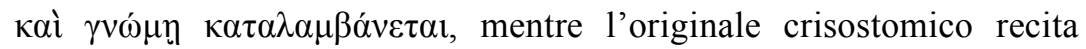

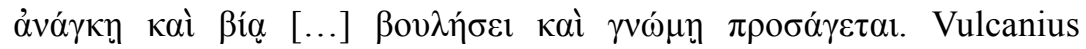
traduce la lezione di Crisostomo rendendola con "necessitate atque vi [...] voluntate et libera animi sententia agitur", desumendo il verbo da un esemplare di Crisostomo e non dalla Catena.

Alla luce dei dati storici e filologici sopra presentati, rimane comunque indubitabile che il testo della Catena secondo il dettato di $\mathbf{P}$ sia quanto di più prossimo possediamo al modello greco utilizzato da Vulcanius: per questo è parso opportuno inserirlo a fronte della traduzione al fine di dare un termine di paragone per la traduzione dell'umanista di Leida.

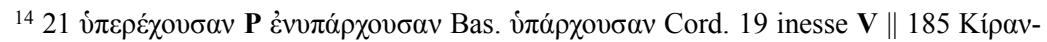

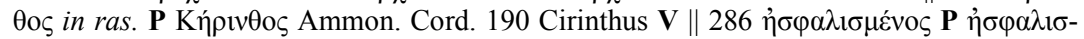

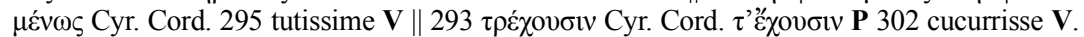
In apparato segnalerò comunque casi assai meno probanti come $43 \dot{\alpha} \rho \chi \eta^{2}$ Bas. Cord. ở $\chi$ i $\mathbf{P} 43$ principium $\mathbf{V}$, in cui una lezione palesemente errata venne corretta sulla base del contesto. Davanti alla prova codicologica cadono anche altri elementi che a un primo sguardo sembrano distanziare la traduzione di Vulcanius da $\mathbf{P}$, che andranno invece spiegati altrimenti. La citazione di Eunomio ai r. 138-139 / 140-142, che in latino si presenta più ampia rispetto al greco, sembra una resa libera del traduttore, intenzionato a chiarire i sottintesi dell'originale (cf. n. 21). In merito ai nomi delle fonti, nel codice greco le loro forme sono assai variabili (come si può vedere nel testo, dove sono state mantenute con il solo scioglimento delle abbreviazioni), mentre in quello latino appaiono in forma più stringata: tuttavia la discrepanza sembra dovuta a una razionale uniformazione adottata da Vulcanius piuttosto che a una caratteristica propria di un diverso esemplare greco da lui impiegato. Infine, anche se nella traduzione mancano il titolo del codice greco e la menzione del nome della prima fonte, tuttavia non sappiamo che cosa Vulcanius avrebbe voluto scrivere in cima al f. $32 \mathrm{r}$ iniziale, dove è rimasto uno spazio vuoto di circa tre righe. 


\section{Vulcanius traduttore: metodo di lavoro e possibili scopi della traduzione}

A differenza di altre traduzioni raccolte nel medesimo codice, ${ }^{15}$ la Catena in Ioannem è vergata in bella copia, con grafia posata, impaginazione accurata ${ }^{16}$ e pochissime correzioni in scribendo. L'oscillazione tra materiali in minuta e altri in bella copia è caratteristica saliente di $\mathbf{V}$ in particolare e degli altri autografi di Vulcanius in generale, e interessa anche le lezioni introduttive ai corsi su Senofonte (alla copia definitiva che si legge ai f. 42r-44v del nostro stesso codice corrisponde la minuta ai f. 189r-191v del codice Leiden, Universiteitsbibliotheek, ms. Vulc. 36) ed Esiodo (in questo caso minuta e bella copia sono addirittura rilegate una di seguito all'altra, non senza errori, ai f. $47 \mathrm{v}-55 \mathrm{v}) .{ }^{17}$ Del resto le minute di Vulcanius, sia nelle vesti di scrittore sia in quelle di traduttore, sono sempre costellate da un numero tale di errori e correzioni, cancellature e riscritture, da imporre necessariamente la stesura di una seconda copia per garantire una migliore leggibilità al suo lavoro.

La lenta maturazione della versione definitiva dei testi di Vulcanius non è in contrasto con il modus vertendi che emerge dall'analisi della traduzione della Catena, dove egli appare costantemente impegnato alla difficile ricerca di compromessi tra l'aderenza al dettato greco originale, lo scioglimento delle sue asprezze e una ricerca di espressività nel latino. Tale approccio produce una traduzione generalmente corretta, con poche e trascurabili sbavature. ${ }^{18}$ Il confronto tra le prime righe del testo

15 Per esempio la traduzione di Giorgio Moschampar ai f. 86r-87v, analizzata in Silvano 2014 (come a n. 2), 245-246.

16 Tale caratteristica interessa anche l'accurata collocazione a margine dei nomi degli autori greci da cui provengono gli estratti. Sono inseriti in caratteri maiuscoli e in collocazione sporgente sul margine sinistro ai f. $32 \mathrm{r}-33 \mathrm{r}, 34 \mathrm{r}$ e $35 \mathrm{r}-36 \mathrm{v}$, su quello destro ai f. $33 \mathrm{v}$ e $34 \mathrm{v}$.

${ }^{17}$ Cf. Stefani 2018a (come a n. 2), 256-257, e 2018b (come a n. 4), 209-210 e 226.

${ }^{18} \mathrm{Al}$ r. 59 manca la traduzione di $\delta \varepsilon i \xi \alpha \varsigma$ (r. 60) nella serie di cum narrativi in coordinazione; al r. 114 Vulcanius traduce il participio $\mu v \theta \varepsilon v ́ \omega v$ (r. 112) come nome proprio "Mytheon" (si noti che nel codice di Parigi la seconda $v$ è di ardua lettura); al r. 229 dicimus presuppone un errore nella lezione del codice greco discendente da $\mathbf{P}$ o nella lettura da parte di Vulcanius, che traduce $\lambda \dot{\varepsilon} \gamma o \mu \varepsilon v$ al posto della recta lectio $\gamma \varepsilon ́ \gamma o v \varepsilon v$ (r. 225); al r. 318 scrive "Filius" al posto di "Spiritus". Dal momento che queste lezioni sono autografe ed è al contempo difficile stabilire se l'errore sia dovuto a Vulcanius o a un difetto del suo codice greco, ho preferito lasciarle nel testo e commentarle in apparato. 
nell'originale greco (r. 2-9) e quelle corrispondenti nella traduzione di Vulcanius (r. 1-8) permetterà di commentare alcuni di questi aspetti: ${ }^{19}$

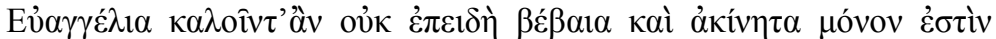

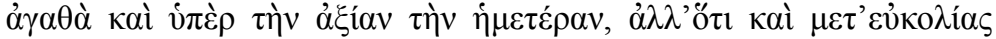

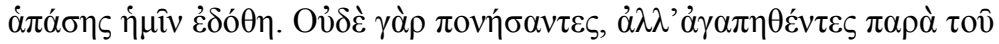

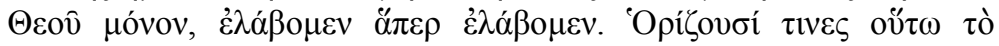

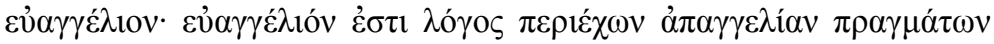

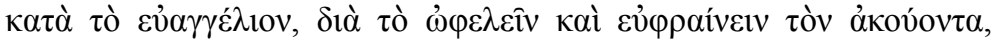

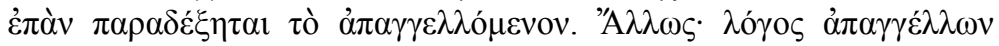

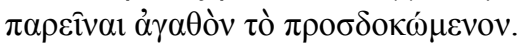

Evangelia dicuntur non tantum quia firma atque immobilia sunt bona et meritum nostrum excedentia, verum etiam quia omni cum facilitate nobis sunt data. Neque enim nostro labore, sed prae solo Dei amore, ea quae consecuti sumus ab ipso accepimus. Nonnulli Evangelium ita definiunt: Evangelium est sermo continens annuntiationem rerum idque bono ac fausto nuntio, ideo quod iuvent et delectent audientem, cum id quod nunciatur perceperit. Aliter: sermo annuncians praesens esse bonum id quod expectabatur.

Come si può vedere da questo esempio, Vulcanius procede ricercando un ordo verborum ancor più lineare dell'originale: "tantum" per $\mu$ óvov ed "etiam" per kaí sono ricollocati di seguito a "non" e "verum" e davanti alle due congiunzioni causali, rese in modo identico con "quia" a fronte di un originale in variatio ( $\dot{\epsilon} \pi \varepsilon 1 \delta \grave{\eta}[.$.$] ö \tau)$. Identica preoccupazione si ha nel chiarimento di una lezione del testo greco non del tutto chiara: vi $x \dot{\rho} \rho$ è reso da un participio, "excedentia", per esplicitare che preposizione e accusativo si collocano come ulteriore nome del predicato in sequenza con "firma e immobilia" (si noti anche che "excedo" regge l'accusativo, garantendo così una costruzione affine all'originale);

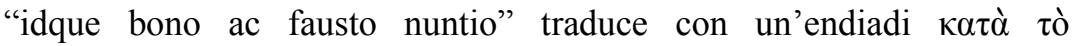

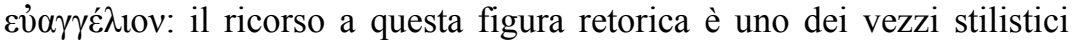
ricorrenti nelle traduzioni di Vulcanius, ${ }^{20}$ che qui risolve etimologica-

\footnotetext{
${ }^{19}$ Ho scelto di commentare la sezione iniziale perché il lettore possa cogliere l'aspetto della Catena originale in un passaggio in cui le due fonti (Giovanni Crisostomo e Origene) sono state rielaborate per permetterne l'unificazione e non semplicemente estratte ad verbum dalle fonti greche. Un confronto più esteso e puntuale potrà essere svolto infra confrontando l'edizione critica della traduzione con il testo greco riportato accanto.

${ }^{20}$ Cf. Silvano 2014 (come a n. 2), 247. Altrove invece opera al contrario, usando un elemento solo per rendere un'endiadi del greco: cf. e.g. r. 62 / 63, dove l'espressione

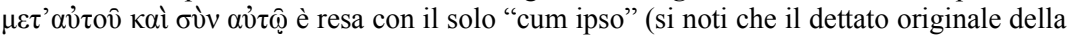




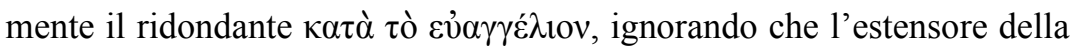

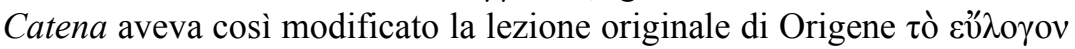
("secondo verisimiglianza"). Un'altra soluzione efficace con discosta-

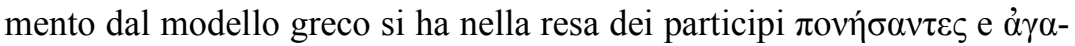
$\pi \eta \theta \varepsilon \dot{v} \tau \varepsilon \varsigma$ in forma nominale con due complementi di causa "labore" $\mathrm{e}$ "amore": con questo espediente Vulcanius esplicita tanto il valore causale quanto il riferimento al nominativo sottinteso mediante l'aggiunta del possessivo "nostro"; inoltre $\pi \alpha \rho \alpha \grave{~ \tau o v ̂ ~ \Theta \varepsilon o v ̂ ~ v i e n e ~ i n t e s o ~ d a ~}$ Vulcanius come un costrutto ámò koıvov̂ da scindere nel genitivo "Dei" (riferito ad "amore") e nel complemento di origine "ab ipso" (da riferire

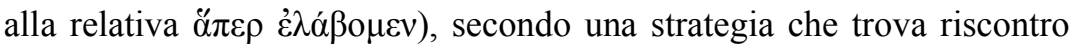
anche altrove nel testo in corrispondenza di passi poco perspicui. ${ }^{21}$

Da ultimo, prima di presentare l'edizione della traduzione di Vulcanius, occorre domandarsi con quale obiettivo essa sia stata realizzata. La collocazione della versione latina accanto a materiali riguardanti i corsi universitari, come la lezione introduttiva su Omero e quella su Senofonte, potrebbe suggerirne la pertinenza con l'insegnamento universitario: nel commento ai classici Vulcanius spesso rintraccia e sottolinea argomenti conformi alla morale cristiana $^{22}$ e altre volte riutilizza mate-

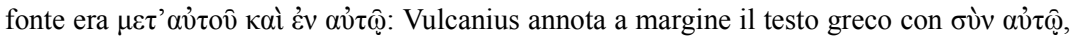
lezione del codice di Parigi, come era lecito attendersi).

${ }^{21}$ Cf. e.g. la citazione di Eunomio ai r. 138-139 / 140-142, dove Vulcanius rende

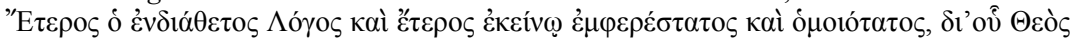

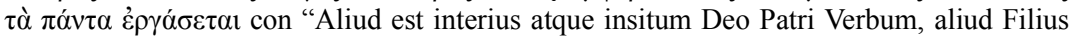
et Verbum Dei, per quod cuncta Deus creavit, interiori atque insito simillimum". Poiché Vulcanius leggeva un discendente di $\mathbf{P}$ e anche in Cordier il dettato della catena è identico, è ragionevole ipotizzare che la divergenza sia dovuta a soluzioni proprie del nostro traduttore, per meglio chiarire la blasfemia che l'originale lascia nel vago

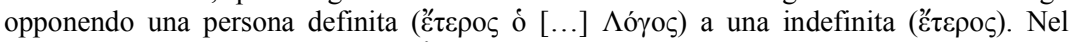
primo membro Vulcanius rende $\varepsilon \dot{v} \delta i \alpha ́ \theta \varepsilon \tau o \varsigma$ con l'endiadi "interius atque insitum" e

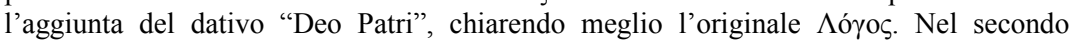
membro, Vulcanius aggiunge ex novo il nominativo "Filius et Verbum Dei" a completa-

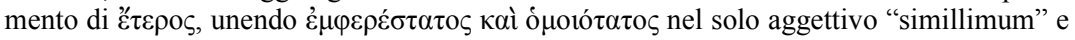
recuperando la coppia nei dativi "interiori atque insito" che chiarisce oltre ogni dubbio

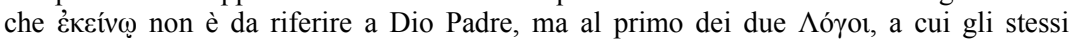
aggettivi erano riferiti nel primo colon. Si noti inoltre che per le citazioni bibliche, solitamente molto brevi, Vulcanius non sembra ricorrere alla Vulgata, ma a traduzioni proprie, anche per meglio integrarle nel testo in cui sono inserite.

${ }^{22} \mathrm{Si}$ veda per esempio la possibilità di leggere in senso tanto classico quanto cristiano le virtù del buon principe elencate nei Prolegomeni alla Ciropedia di Senofonte in Stefani 2018 b (come a n. 4), 212 e 220 r. 64-67. 
riali di altri autori. ${ }^{23}$ È quindi possibile che abbia approntato questa traduzione per utilizzarne delle parti in un eventuale commento di alcuni brani del Nuovo Testamento. Tuttavia il commento ai primi versetti del Vangelo secondo Giovanni poteva offrire elementi per un dibattito sulle questioni trinitarie, in particolare sulla consustanzialità tra il Padre e il Figlio: non si può quindi escludere un collegamento con le altre traduzioni di testi teologici, tutti su argomenti costantemente dibattuti nella storia del Cristianesimo. Non va infine tralasciata la possibilità che Vulcanius ritenesse quegli estratti preziosi in quanto testimonianza di opere all'epoca sconosciute a lui e ai suoi allievi, perché inedite o difficilmente reperibili, e perciò degne di attenzione e di traduzione: si tratta degli stessi interessi che nei secoli successivi hanno spinto i filologi a studiare questo tipo di testi, anche tramite il solo prelievo degli estratti da singoli autori.

Sebbene sia difficile definire quale di queste ragioni abbia spinto Vulcanius a intraprendere la traduzione, tuttavia ognuna di esse è coerente con il suo composito profilo di docente universitario e studioso di testi classici e cristiani. In conclusione, questa versione latina della Catena in Ioannem appare da un lato un'interessante testimonianza delle prassi di traduzione dal greco al latino nell'Umanesimo nordeuropeo del Cinque-Seicento, e dall'altro una testimonianza di un certo rilievo delle modalità di diffusione della letteratura patristica greca nell'Europa riformata, attraverso la circolazione non solo di opere complete, ma anche di più brevi estratti inseriti entro compilazioni dai tratti assai peculiari come le Catenae. ${ }^{24}$

Università degli Studi di Torino matteo.stefani@unito.it

${ }^{23}$ Sui prelievi da opere di Melantone cf. Stefani 2018a (come a n. 2), 258-259, e 2018b (come a n. 4), 211 e n. 10.

${ }^{24}$ Per un inquadramento generale arricchito da esempi specifici sulla diffusione della letteratura patristica nell'Umanesimo italiano e nordeuropeo: S. Gentile (ed.), Umanesimo e Padri della Chiesa. Manoscritti e incunaboli di testi patristici da Petrarca al primo Cinquecento (Caleppio di Settala, 1997); M. Cortesi, C. Leonardi (ed.), Tradizioni patristiche nell'Umanesimo. Atti del convegno di studi promosso dalla Società Internazionale per lo Studio del Medioevo Latino, Firenze, 6-9 febbraio 1997 (Firenze, 2000); M. Cortesi (ed.), I Padri sotto il torchio. Atti del convegno di studi promosso dalla Società Internazionale per lo Studio del Medioevo Latino, in collaborazione con l'Università di Firenze e l'Università di Pavia, Firenze, 25-26 giugno 1999 (Firenze, 2002); Ead. (ed.), Padri greci e latini a confronto, secoli XII-XV (Firenze, 2004). 


\section{Appendice: edizione}

\section{Criteri editoriali}

Testo. Nel fornire l'edizione della traduzione di Vulcanius con a fronte il testo greco della sezione iniziale della Catena secondo il codice Paris, Bibliothèque nationale de France, ms. gr. 209 (P), sono state sciolte tutte le abbreviazioni; l'interpunzione e l'uso delle maiuscole sono stati adeguati alle consuetudini moderne; la posizione dei versetti giovannei a centro rigo e quella dei nomi degli autori in genitivo al principio di ciascun estratto è editoriale (cf. n. 14 e 16 per il loro aspetto nei due manoscritti).

Apparati. Ogni testo è dotato di propria numerazione e di proprio apparato critico. Quello del testo latino segnala tutti i dettagli che si riscontrano sull'autografo di Vulcanius. Quello del testo greco si limita a indicare le correzioni introdotte sulla base delle fonti in corrispondenza di scritture del tutto insostenibili in $\mathbf{P}$ e le lezioni più rilevanti che separano quest'ultimo dall'accordo tra ciascuna fonte e la versione della Catena di identica famiglia edita da Cordier (Cord.), in modo da evidenziare a quale variante Vulcanius si accodi (cf. n. 10 e 14). Nell'apparato delle fonti, le abbreviazioni sono tratte, con qualche adattamento redazionale, da G.W.H. Lampe, A Greek Patristic Lexicon, Oxford, 1969. 


\section{Catena in Ioannem 1.1-13}

Paris, Bibliothèque nationale de France, ms. gr. 209 (P), f. 1r-10v

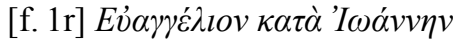

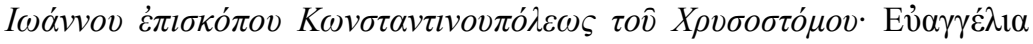

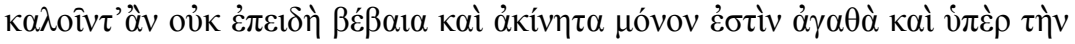

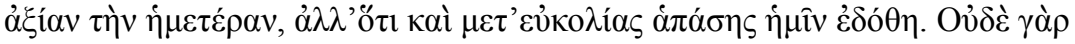

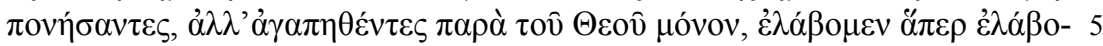

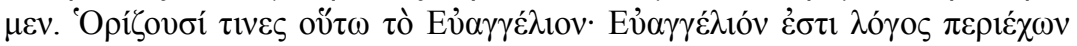

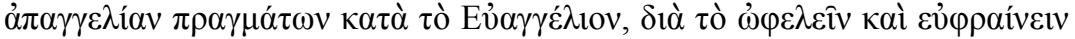

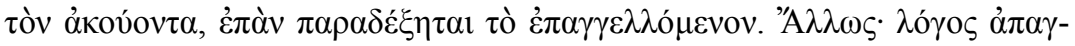

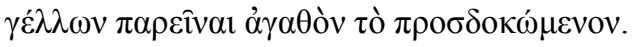

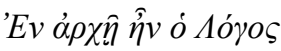

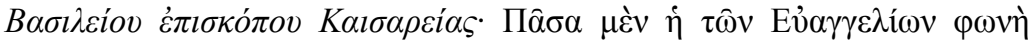

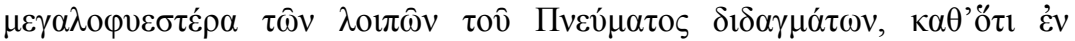

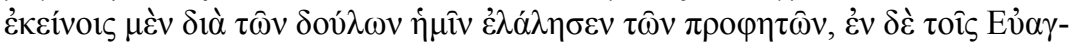
$\gamma \varepsilon \lambda$ íors $\alpha$ ชo

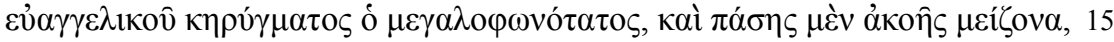

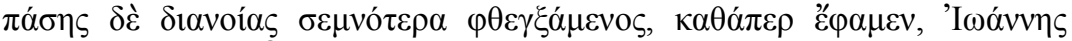

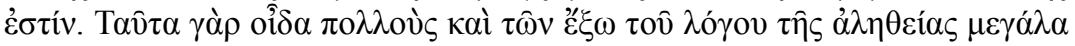

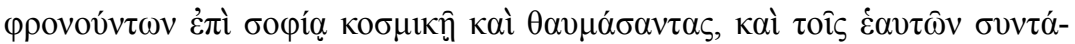

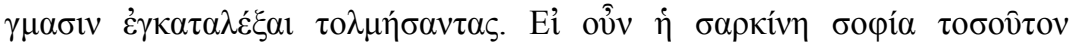

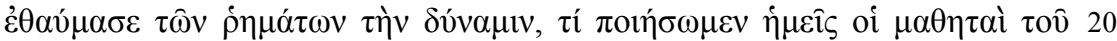

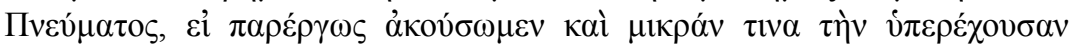

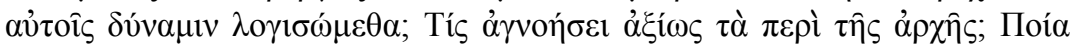

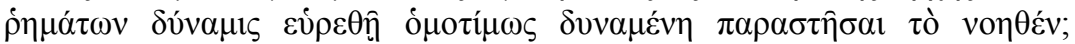

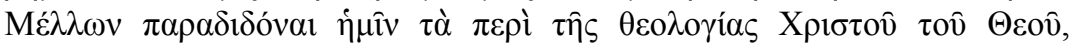

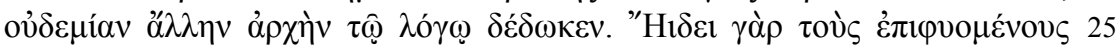

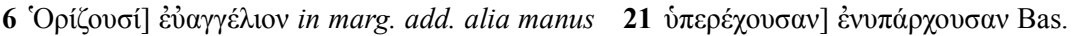

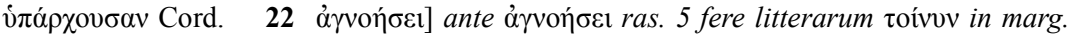

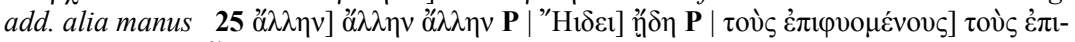

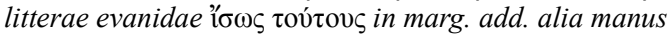

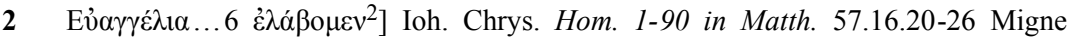

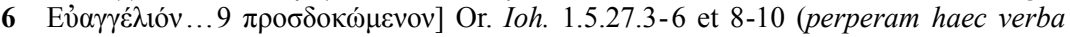

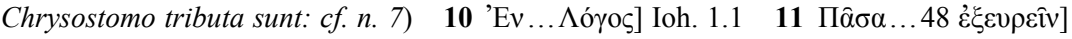
Bas. Hom. 31.472.19-476.9 Migne (passim) 


\section{Catena in Ioannem 1.1-13}

Leiden, Universiteitsbibliotheek, ms. Vulc. 9 (V), f. 32r-36v

[f. 32r] Evangelia dicuntur non tantum quia firma atque immobilia sunt bona et meritum nostrum excedentia, verum etiam quia omni cum facilitate nobis sunt data. Neque enim nostro labore, sed prae solo Dei amore, ea quae consecuti sumus ab ipso accepimus. Nonnulli Evange-

5 lium ita definiunt: Evangelium est sermo continens annuntiationem rerum idque bono ac fausto nuncio, ideo quod iuvent et delectent audientem, cum id quod nunciatur perceperit. Aliter: sermo annuncians praesens esse bonum id quod expectabatur.

\section{In principio erat Verbum}

10 Basilii: Omnis quidem Evangeliorum vox reliquis omnibus Sancti Spiritus documentis magnificentior est, siquidem in illis per prophetas servos nobis est locutus, in Evangeliis ipsemet per se Dominus nos est allocutus. At vero inter Evangelicos praecones maxime sublimis est omnique auditu maiora atque omni intellectu superiora sonans, ut

15 diximus, Ioannes. Haec enim verba scio multos etiam eorum qui extra rationem veritatis de mundana sapientia gloriantur admiratos esse scriptisque suis inserere ausos. Si ergo mundana sapientia tantopere admirata est verborum vim, quid nos Spiritus Sancti discipuli faciemus, si perfunctorie ea audiamus et exiguam quandam vim iis inesse existi-

20 memus? Quisnam digne quae sunt circa principia cognoscet? Quaenam verborum virtus inveniatur quae possit cognitum pro ipsius dignitate explicare? Cum de theologia Christi tractaturus sit, nullum aliud exordium orationi quam principium praetulit. Sciebat enim Spiritus Sanctus adversarios gloriae Unigeniti dicturos: "Si genitus est, non

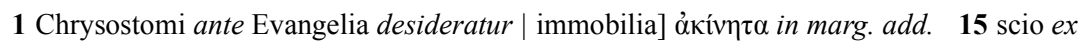
sciet corr. 19 inesse] $c f . n .14$ 


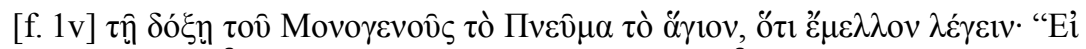

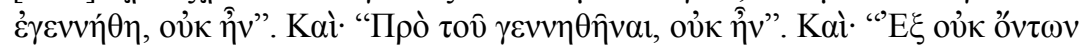

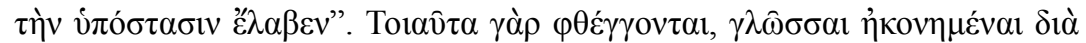

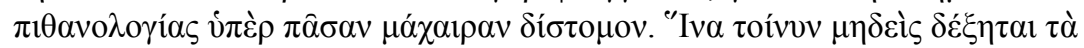

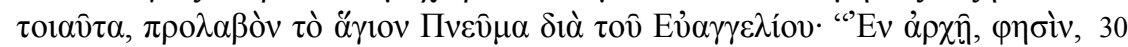

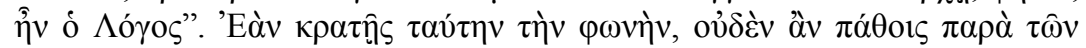

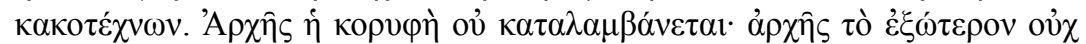

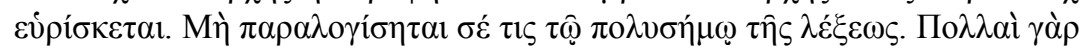

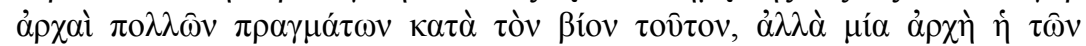

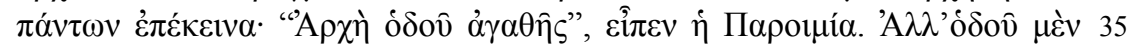

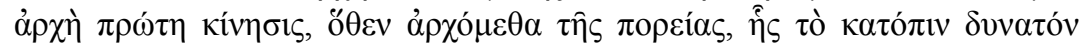

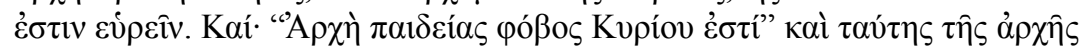

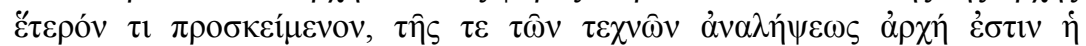

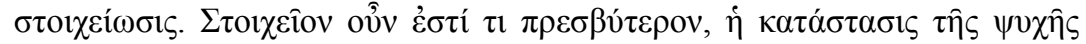

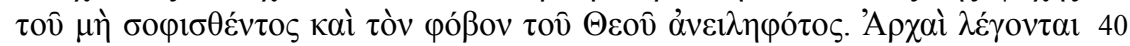

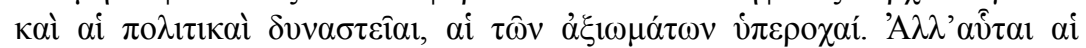

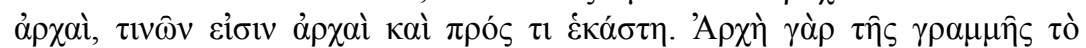

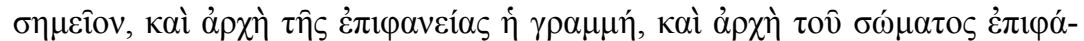

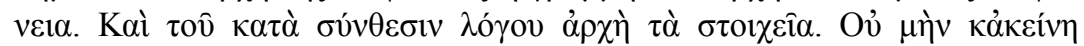

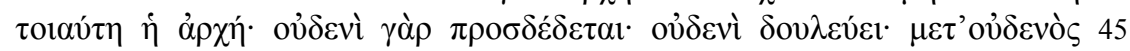

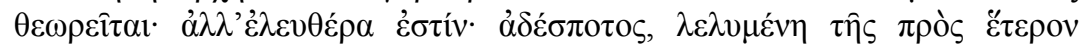

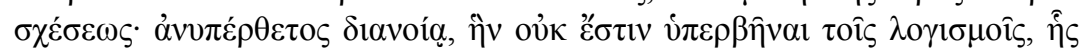

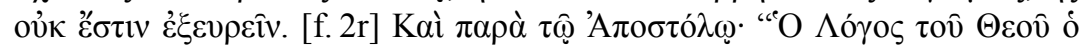

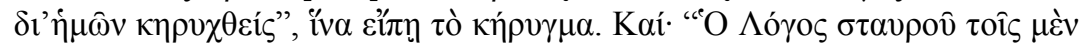

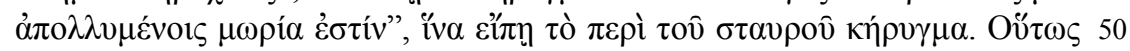

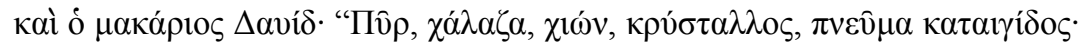

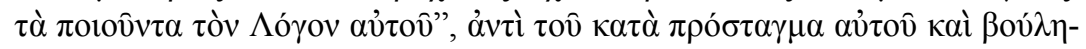

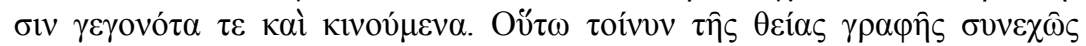

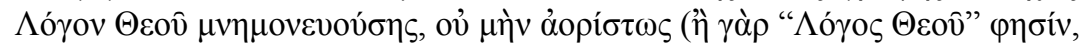

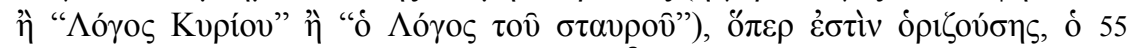

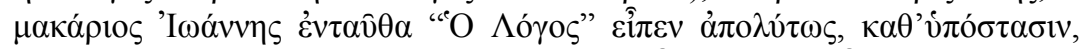
őv

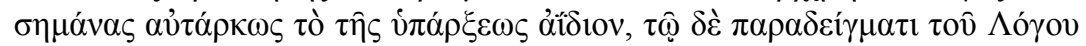

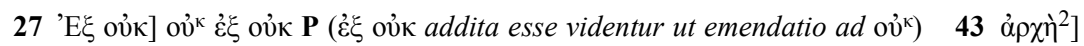

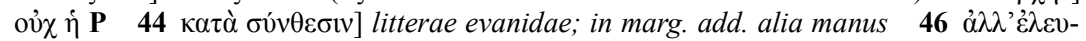
$\theta \dot{\varepsilon} \rho \alpha] \alpha \dot{\alpha} \lambda \lambda^{\prime} \lambda^{\prime} \dot{\varepsilon} \lambda \varepsilon v \theta \dot{\varepsilon} \rho \alpha \dot{\varepsilon}_{\sigma} \sigma \tau^{\prime} \mathrm{P} \mathbf{P}$ in marg. corr. alia manus

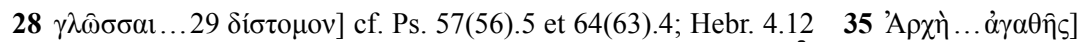

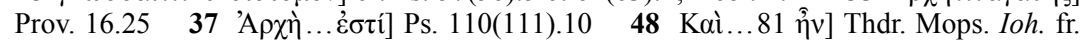
2.113-147 Devreesse (perperam haec verba Basilio tributa sunt: $c f . n$. 7) | ${ }^{\circ} \mathrm{O} \ldots 49$

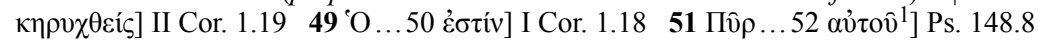


25 erat". Et: “Antequam generaretur, non erat". Et: "Ex iis quae non sunt hypostasim acceperit". Talia enim loquuntur, linguam persuasibilitate sermonis quovis gladio ancipite penetrantiorem habentes. Ne igitur huiusmodi opiniones cuiuspiam animum invadant, praeoccupans Spiritus Sanctus per Evangelium: "In principio, inquit, erat Verbum". Si

30 hanc vocem tenueris, nihil tibi hi malis suis artibus officient. Principii summitas non comprehenditur: principio ulterius nihil invenitur. Ne te quispiam decipiat varia vocis significatione. Multa enim principia sunt multarum rerum in hac vita, sed unum est principium omnium supremum: "Principium bonae viae", ait Proverbiorum liber. Sed viae 35 quidem principium primus motus est unde iter incipimus, quo prius aliquid inveniri potest. Et: "Principium sapientiae timor Domini est" et hoc principium aliquid antecedit et artium comprehensionis principium est institutio. Est igitur aliquod antiquius principium: constitutio animae nondum factae sapientis et domini timorem adeptae. Principia 40 etiam dicuntur civiles potentatus, dignitatum excellentiae. Sed haec ipsa principia aliquorum sunt principia et ad aliquid [f. 32v] unaquaeque. Principium enim lineae punctum, et principium superficiei linea, et principium corporis superficies, et compositae orationis principia sunt litterae. Illud vero de quo agimus principium non tale est: nulli 45 alligatum est, nulli servit, cum nullo consideratur, sed liberum est, sine domino, expers plane cuiusvis ad aliud respectus, cogitatione incomprehensibile, ultra quod aliquid inveniri non potest. Et ab Apostolo: "Verbum Dei quod per nos praedicatum est", ut dicat praedicationem. Et: "Verbum crucis iis quidem qui perierunt stultitiae est", ut dicat 50 crucis praedicationem. Ita etiam Beatus David: "Ignis, grando, nix, cristallus, spiritus procellae: facientia verbum ipsius", quasi diceret iuxta praescriptum ac voluntatem eius facta simul et mota. Cum itaque divina scriptura passim Verbi Dei mentionem faciat, non quidem indefinite (aut enim "Verbum Dei" ait aut "Verbum Domini" aut

55 "Verbum crucis") atque id quod est definiat, Beatus Ioannes hic absolute, secundum hypostasim absque alicuius adiectione et definitione. Cum igitur dixisset "In principio erat Verbum" satisque apte significasset substantiae aeternitatem et per exemplum Verbi non solum

27 penetrantiorem ex acutio corr. 28 animum] vel animam (aim V) 31 summitas] корифи́ in marg. add. 43 per ante compositae del. 47 qua ante ultra del. | Et ab Apostolo] cf. p. 32249 quidem ante crucis del. | iis ex perditis corr. ut vid. | iis quidem qui perierunt] $\alpha \pi \mathrm{o} \lambda \lambda v \mu \varepsilon \dot{v}$ orৎ in marg. add. 


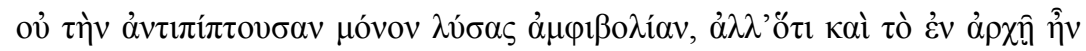

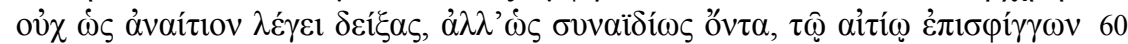

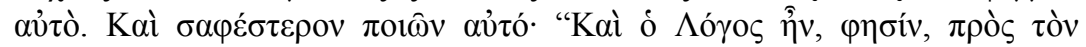

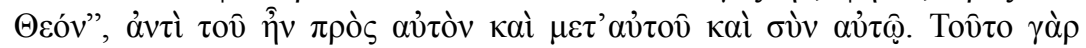

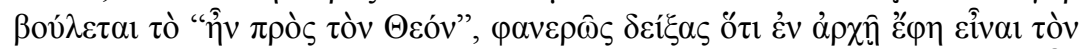

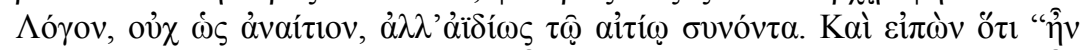

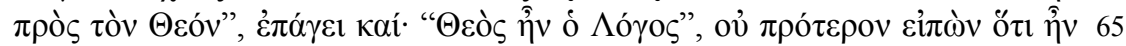

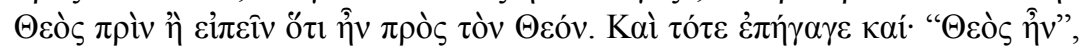

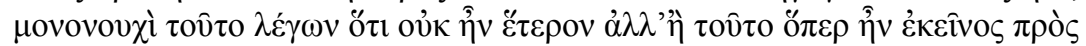

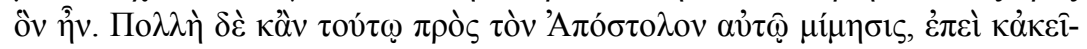

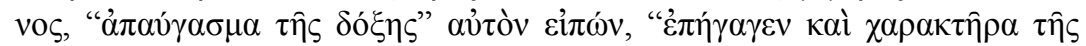

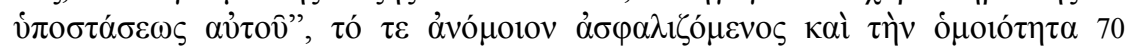

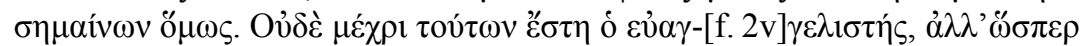

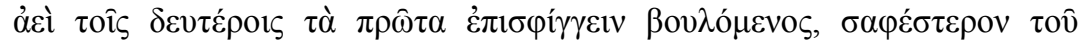

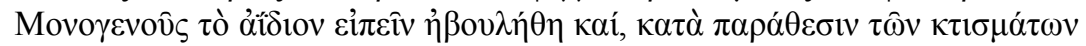

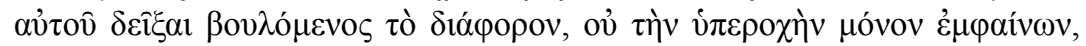

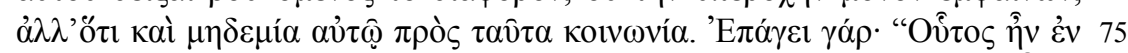

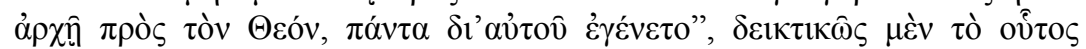

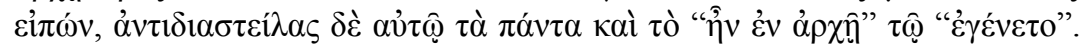

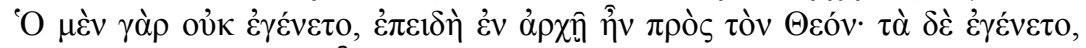

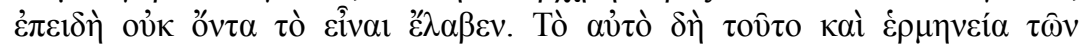

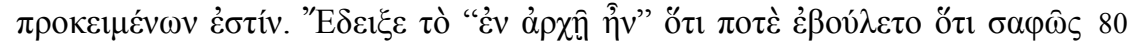

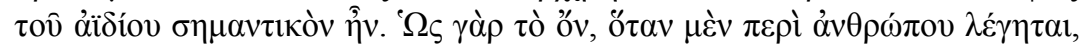

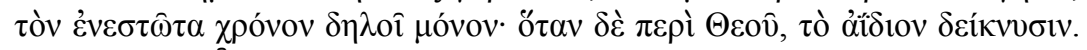

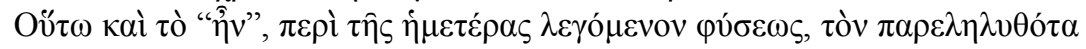

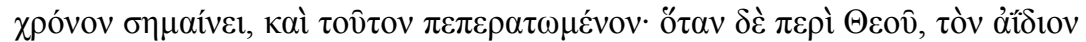

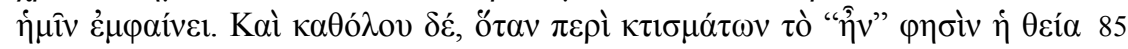

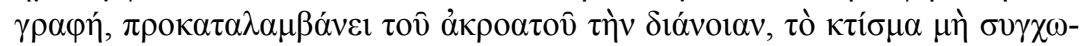


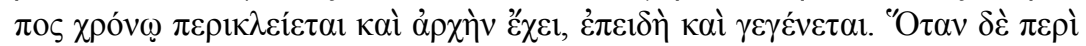

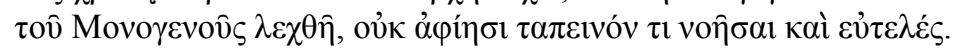

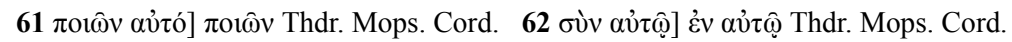

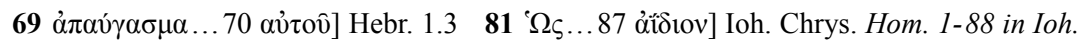
59.39.42-48 Migne (perperam haec verba Basilio tributa sunt: $c f$. . $n .7) \quad 87$ Паิv ...89

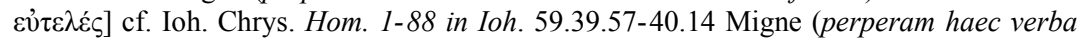
Basilio tributa sunt: cf. $n$. 7) 
obiectionis dubium solvisset, sed $* * *$ quod in principio erat non 60 tanquam ảvaítiov (hoc est nullam causam agnoscentem) sed tanquam ab aeterno existentem, uno cum causa ipsa vinculo constringit. Et manifestius id faciens: "Et Verbum, inquit, erat apud Deum", pro ad ipsum et cum ipso. Hoc enim significat "Erat apud Deum", aperte ostendens quod in principio dixit esse Verbum, non tanquam causae 65 expers, sed ab aeterno una cum causa existens. Cumque dixisset quod "erat apud Deum", adiicit: "Et Deus erat Verbum", non prius dicens quod erat Deus, donec diceret quod esset apud Deum. Ac tunc adiecit: "Et Deus erat", tantum non hoc dicens, quod non esset aliud quam quod esset ille apud quem erat. Magna vero est huius rei etiam apud 70 Apostulum imitatio, siquidem etiam ille, cum "splendorem gloriae" ipsum dixisset, addit: "Et characterem substantiae eius", pariter dissimilitudinem propulsans et similitudinem significans. Ceterum non in his subsistit Evangelista, sed, quodammodo semper secundis prima devincire volens, manifestius Unigeniti aeternitatem dicere voluit et, ex 75 appositione creaturarum ipsius ostendere volens differentiam, non solum excellentiam eius declarat, sed quod nulla ipsi sit cum eis communio. Subdit enim: "Hic erat in principio apud Deum. Omnia per ipsum facta sunt", demonstrative quidem hoc dicens, distinguens vero ab ipso omnia. Et huic "erat in principio" opponit "facta sunt". Ipse

80 enim factus non est, siquidem in principio erat apud Deum; haec vero facta sunt. Cum enim non essent, esse acceperunt. Idem autem hoc est et praecedentia declarat. Ostendit hoc "in principio erat" quod voluit quod quidem aperte aeternitatem significabat. Quemadmodum enim ens, quando de homine dicitur, praesens tantum tempus significat; 85 quando autem de Deo, aeternum ostendit. Ita etiam "erat" de nostra natura dictum praeteritum [f. 33r] tempus significat, atque hoc quidem finitum; cum vero de Deo, sempiternum nobis indicat. Atque in universum, quando de creaturis dicit "erat", occupat auditoris mentem, non permittens creaturam in se aeternitatem imaginari. Omne enim quod

90 factum est atque omnis homo tempore circumscribitur et principium habet, siquidem et factus est. Cum vero de Unigenito dicitur, non sinit humile quidquam atque exile cogitare.

59 sed ***] verbum desideratur, an demonstravisset? (P $60 \delta \varepsilon \dot{\xi} \xi \alpha \varsigma) \quad 62$ pro ...63 ipso] $\eta^{\uparrow} v$

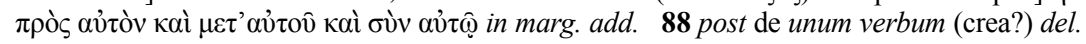

Humanistica Lovaniensia 68.2 (2019), 317-359 


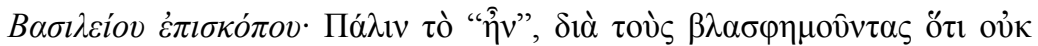

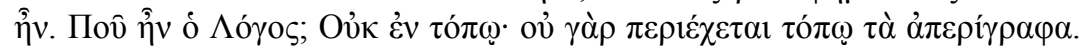

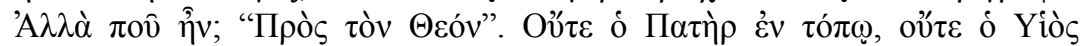

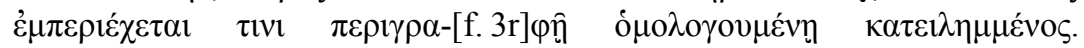

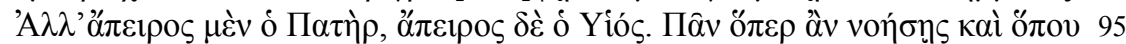

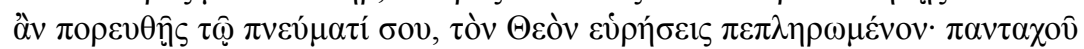

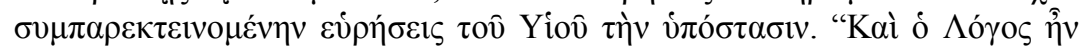

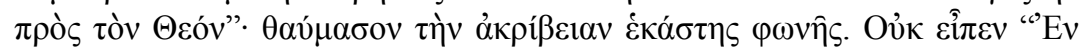

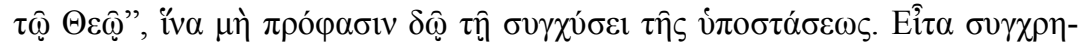

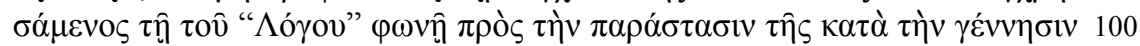

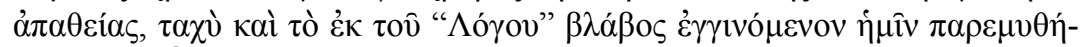

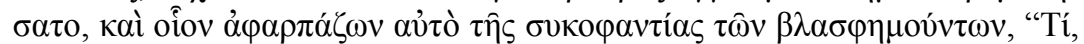

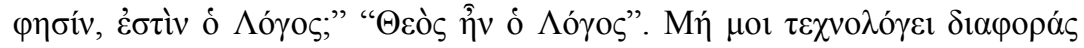

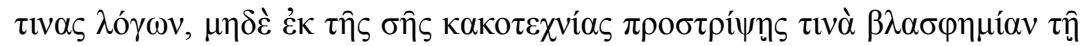

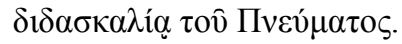

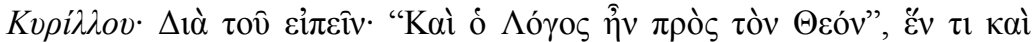

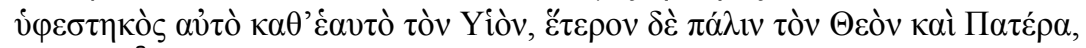

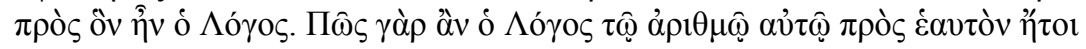

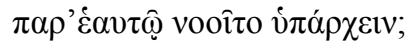

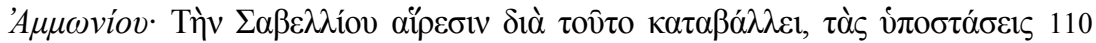

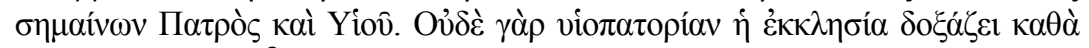
$\mu v \theta \varepsilon v ́ \omega v$ ò $\Lambda$ íß

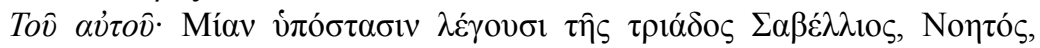

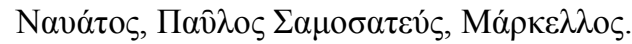

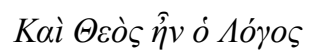

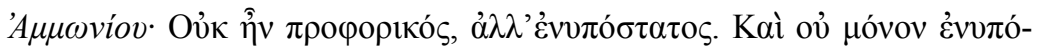

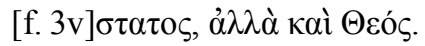

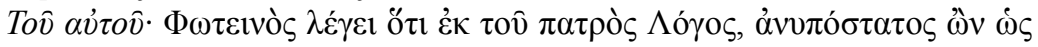

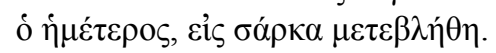

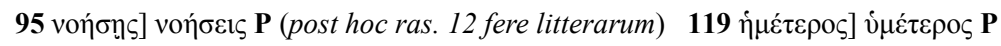

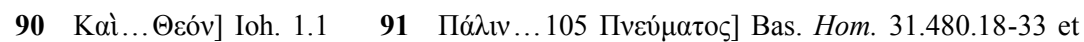

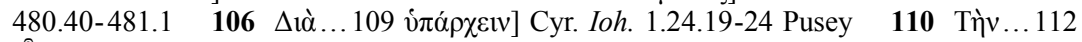

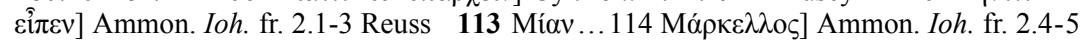

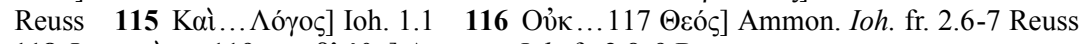

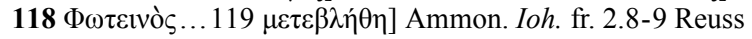




\section{Et Verbum erat apud Deum}

Basilii: Rursus "Erat", propter blasphemantes quod non erat. Ubi 95 erat Verbum? Non in loco: non enim in loco quae sunt incircumscripta continentur. Sed ubi erat? "Apud Deum": neque enim Pater in loco, neque Filius in circumscriptione certa deprehenditur. Sed infinitus Pater, infinitus Filius. Quidquid cogitaveris et quocumque spiritu tuo penetraveris, Deum omnia implere invenies unaque extensam ubique 100 Filii hypostasim. "Et Verbum erat apud Deum": admirare cuiuslibet vocis perfectionem. Non dixit "in Deo", ne confundendae hypostaseos occasionem daret. Deinde cum "Verbi" voce usus esset ad affirmandam generationis impossibilitatem, statim id quod in eo "Verbo" nobis nocere poterat moderatur, ac veluti blasphemantium calumniae eripit 105 qui dicunt: "Quid est Verbum?", cum subiicit: "Deus erat Verbum". Ne mihi verborum differentias excogites, neve ex mala scientia aliquam doctrinae Spiritus blasphemiam incutias.

Cyrilli: Per id quod dicit: "Et Verbum erat apud Deum" unum quid et subsistens in se ipso Filium esse ostendit, alium vero rursus Deum

110 Patrem apud quem erat Verbum. Quo pacto enim Verbum numero ipso ad se ipsum aut apud se ipsum esse intelligatur?

Ammonii: Sabellii haeresim per hoc destruit, hypostases statuens

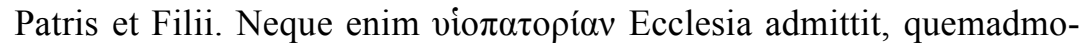
dum Mytheon Africanus dixit.

115 Eiusdem: Unam hypostasim Trinitatis esse dicunt Sabellius, Navatus, Paulus Samosatensis, Marcellus.

\section{Et Deus erat Verbum}

Ammonii: Non erat productitius, sed inexistens. Neque solum inexistens, sed etiam Deus.

120 Eiusdem: Photinus ait quod Verbum ex Patre, cum non exsisteret, ut nostrum aliquis in carnem mutatus fuerit.

95 in $^{1}$ supra lineam add. 104 calumniae] an calumniam? 114 Mytheon] perperam $\mu v \theta \varepsilon u ́ \omega v$ (P 112) pro proprio nomine acceptum est 


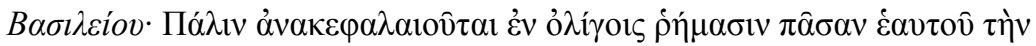

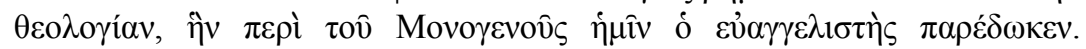

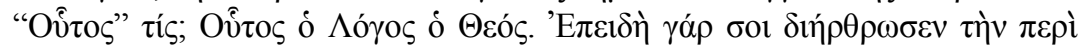

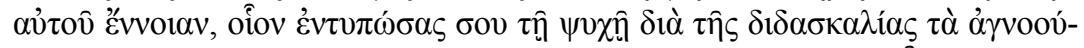

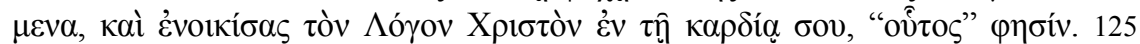

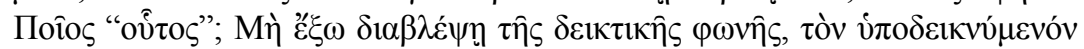

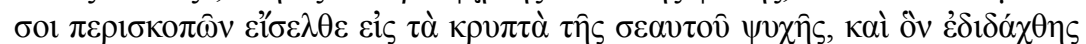

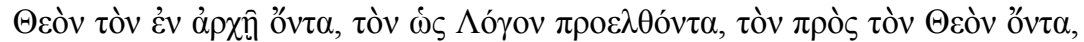

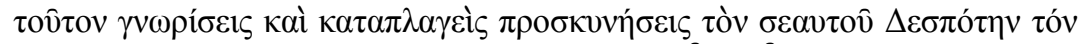

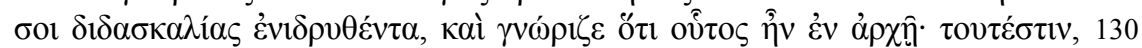

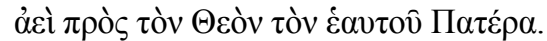

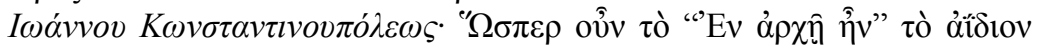

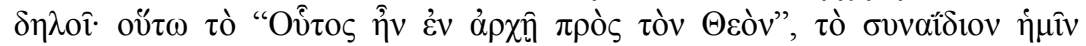

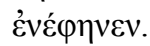

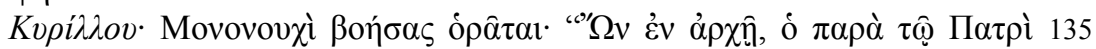

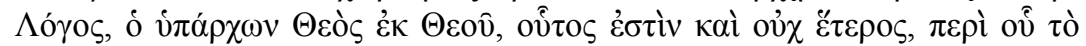

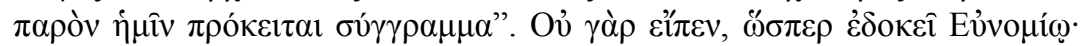

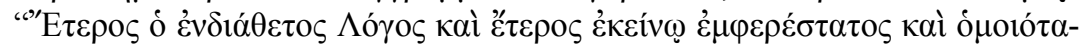

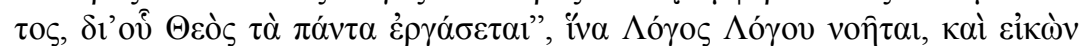

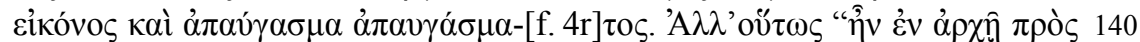

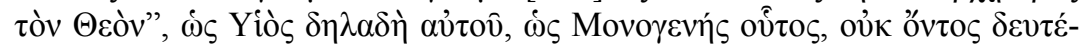


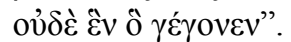

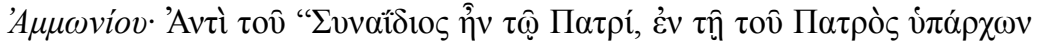

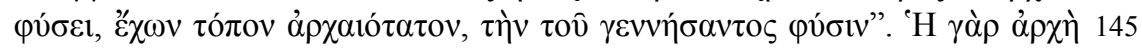

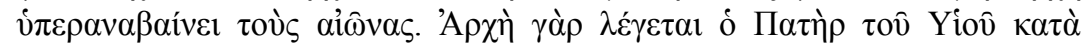

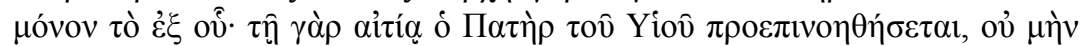

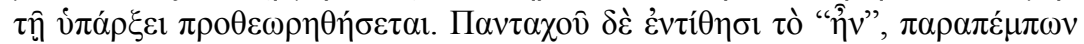

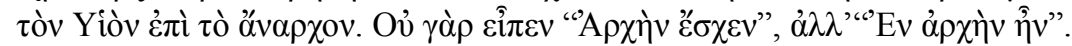

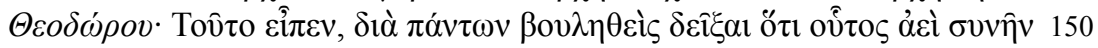

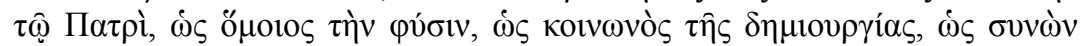

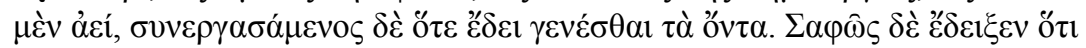

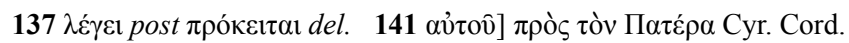

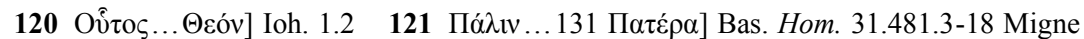

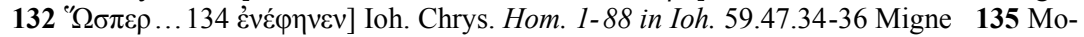

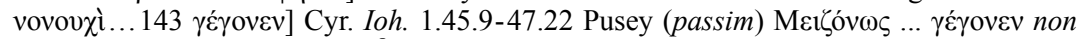

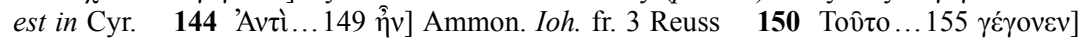
Thdr. Mops. Ioh. fr. 3 Devreesse 


\section{Hic erat in principio apud Deum}

Basilii: Rursum paucis verbis in summam contrahit omnem suam theologiam quam nobis Evangelista de Unigenito tradidit. "Hic" 125 quisnam est? Hic est Verbum Deus. Postquam enim mentem tuam de illo correxit et quasi animae tuae insculpsit quae ignorabas et Verbum Christum cordi tuo inhabitare fecit, "hic" inquit. Quis "hic"? Ne extra vocem demonstrativam respicias, ostensumque tibi considerans ingredere in animae tuae penetralia et qualem didiceris Deum in principio 130 exsistentem, ut Verbum procedentem, ut apud [f. 33v] Deum existentem, hunc cognosces et obstupefactus adorabis tuum ipsius Dominum ac tibi doctrina infixum, et cognosce quod hic erat in principio. Hoc est semper apud Deum Patrem suum.

Chrysostomi: Quemadmodum igitur illud "Erat in principio" aeter-

135 num significat, ita hoc "Hic erat in principio apud Deum" coaeternum nobis ostendit.

Cyrilli: Tantum non clamans videtur: "Hoc Verbum quod in principio erat apud Patrem, hoc quod erat Deus ex Deo, hoc, inquam, et non aliud est de quo librum istum conscribimus". Neque enim dixit, ut

140 Eunomius volebat: "Aliud est interius atque insitum Deo Patri Verbum, aliud Filius et Verbum Dei, per quod cuncta Deus creavit, interiori atque insito simillimum", ut quasi Verbum Verbi et imago imaginis et splendor splendoris intelligatur. Sed ita "erat in principio apud Deum", sicut Filium Verbi ipsius, sicut Unigenitus, nullo existente secundo.

145 Fortiore autem adhuc vinculo astringens: "Et sine ipso, inquit, factum est nihil".

Pro eo ac si diceret: "Coaeternus erat Patri, in Patris natura existens, habens locum vetustissimum, genitoris naturam". Principium enim transcendit saecula. Principium enim dicitur Pater Filii secundum

150 solum ex quo. Siquidem causa Pater Filio praeintelligetur, non autem exsistentia prior considerabitur. Ubique autem inserit "erat", principii carentiam Filio tribuens. Non enim dixit: "Principium nactus est", sed: "Erat in principio".

Theodori: Hoc dixit, volens omnibus modis ostendere quod hic

155 semper aderat Patri, ut similis natura, ut socius creationis, ut semper ei assistens, cooperans vero quando oportebat fieri ea quae in rerum natura sunt. Manifeste autem demonstravit quod hoc "per ipsum" non

140 Aliud... 142 simillimum] cf. $n$. 14 et $21 \quad 147$ Ammonii ante Pro desideratur

Humanistica Lovaniensia 68.2 (2019), 317-359 


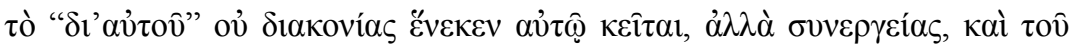

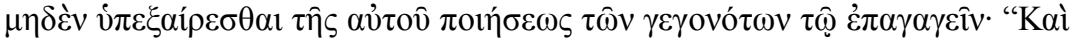

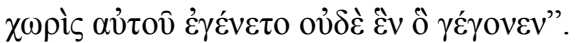

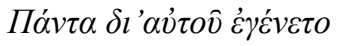

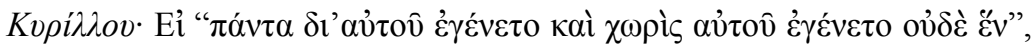

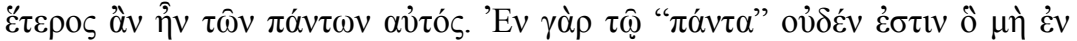

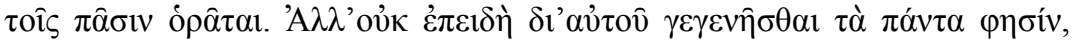

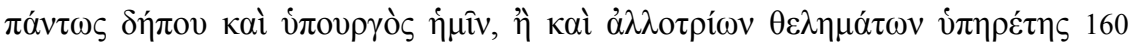

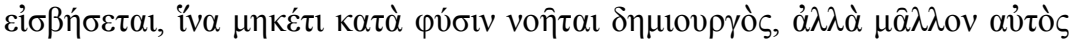

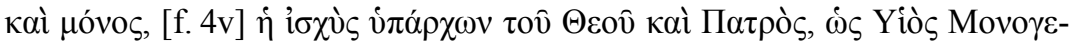

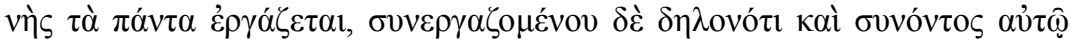

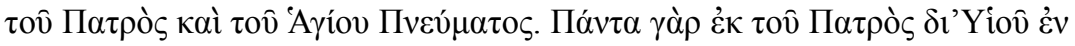

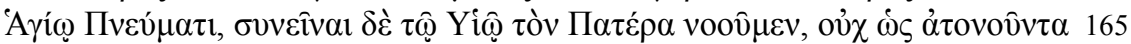

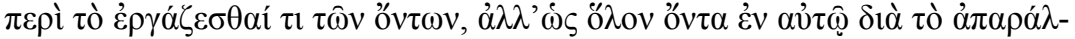

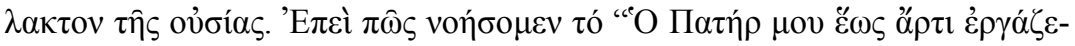

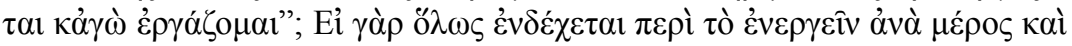

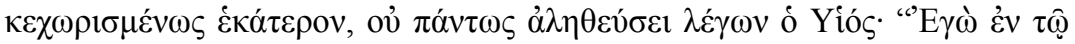

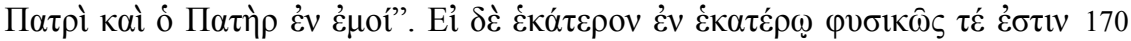

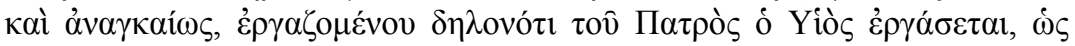

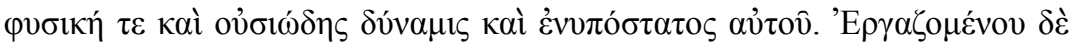

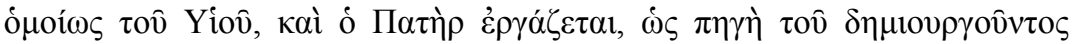

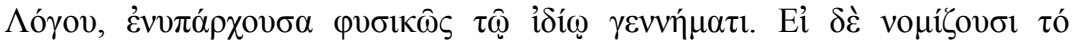

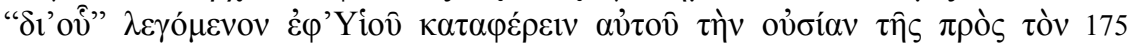

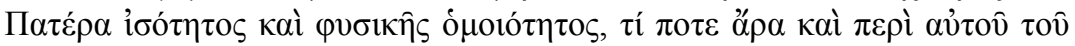

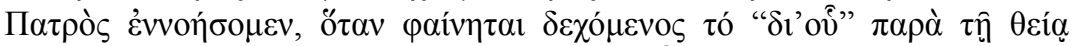

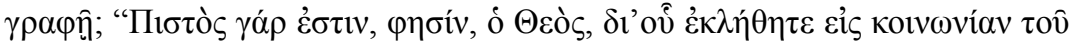

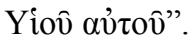

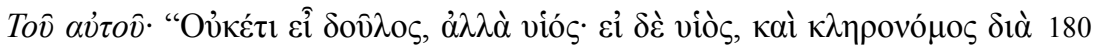

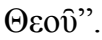

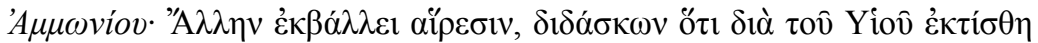

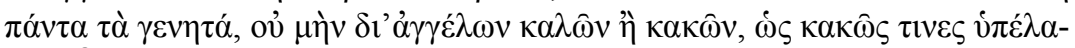

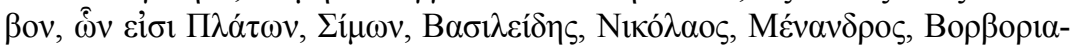

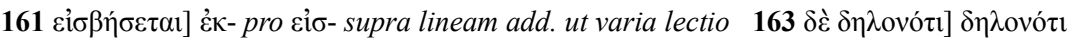

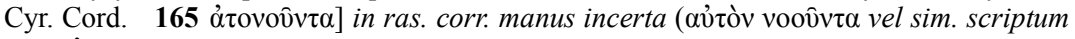

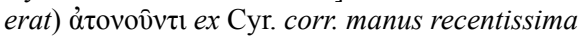

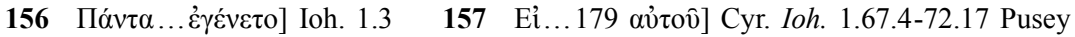

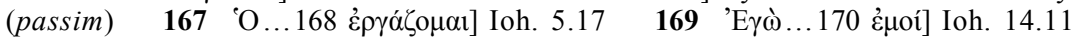

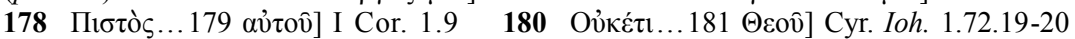
Pusey (= Gal. 4.7) $\mathbf{1 8 2}$ ’А $\lambda \lambda \eta \nu . . .186$ 'A 
ministerii causa ipsi tribuitur, sed cooperationis, nihilque ex iis quae facta sunt ab eius creatione eximi, per id quod inducit: "Et sine ipso 160 factum est nihil quod factum est".

\section{Omnia per ipsum facta sunt}

Cyrilli: Si "omnia per ipsum facta sunt et sine ipso factum est nihil", diversum ipsum esse necesse est ab omnibus. In hoc enim "omnia" nihil est quod non in omnibus deprehendatur. Nec tamen quia omnia 165 per ipsum facta esse dicit, quasi alienae voluntatis minister credendus est ita ut non ex sua natura creator censeatur, imo potius ipse et quidem solus, cum sit fortitudo Dei et Patris, tanquam Filius Unigenitus omnia operatur, cooperante autem, ut manifestum est, atque assistente ipsi Patre et Sancto Spiritu. Omnia enim ex Patre per Filium in Spiritu

170 Sancto simul atque esse cum filio Patrem intelligimus, non quasi impotens sit ad operandum quidquam eorum quae sunt, sed ut totum existentem in ipso propter identitatem substantiae. Siquidem quo pacto intelligemus: "Pater meus usque modo operatur et ego operor"? Si enim fieri potest ut separatim atque divisim alteruter operetur, non 175 omnino verax fuerit Filius dicens: "Ego in Patre et Pater in me". Si autem alter in altero naturaliter existit, operante aliquid Patre, operatur etiam Filius, utpote naturalis atque substantialis eius virtutibus, ipsique inexistens. Similiter operante Filio, etiam Pater operatur, ut operatis Verbis fons, naturaliter Filio suo inexistens. Si vero existimant illud 180 "per quem" de Filio dictum detrahere aliquid ipsius essentiae [f. 34r] ab aequalitate ad Patrem et naturali similitudine, quidnam de Patre ipso sentiemus, cum hoc "per quem" ipsi etiam a divina scriptura tribuatur? "Fidelis enim, inquit, est Deus, per quem vocati estis ad communionem Filii ipsius".

185 Eiusdem: "Non aptius est servus, sed filius: si autem filius, etiam haeres per Deum".

Ammonii: Aliam haeresim profligat, docens quod per Filium creata sunt omnia quae in rerum natura existunt, non autem per angelos bonos aut malos, ut quidam male opinati sunt, ex quibus sunt Plato, Simon,

175 Filius ante Patre del. 182 dicemus ante sentiemus del. 


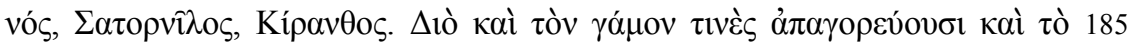

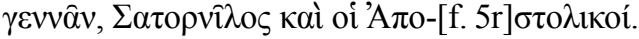

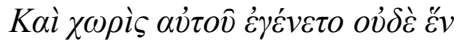

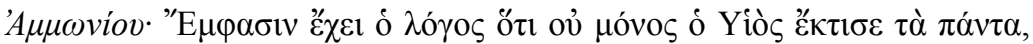

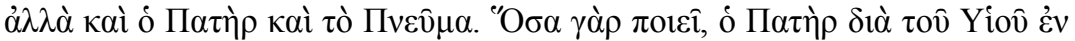

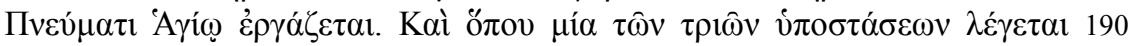

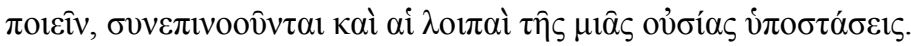

\section{'Ev $\alpha \dot{v} \tau \hat{\omega} \zeta \omega \grave{\eta} \hat{\eta} v$}

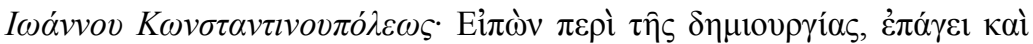

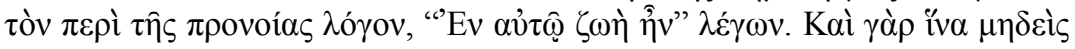

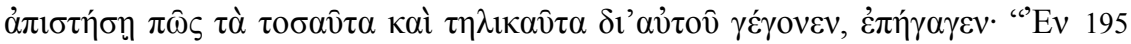

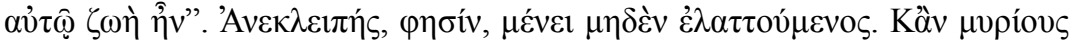

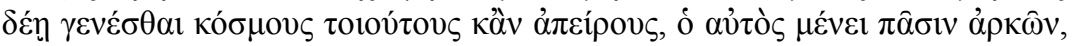

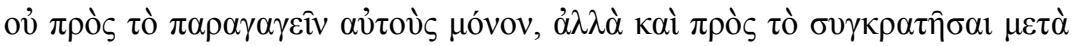

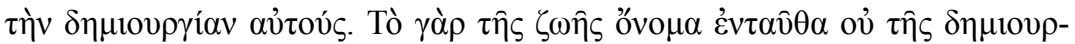

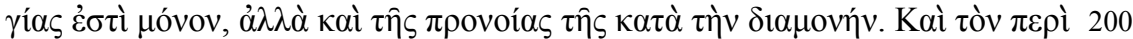

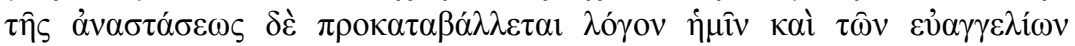

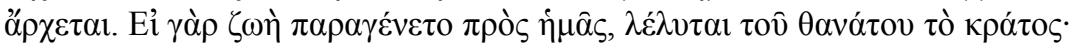

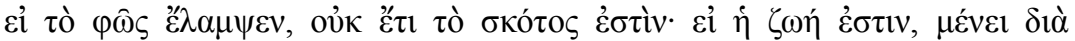

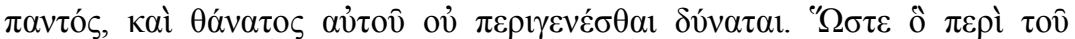

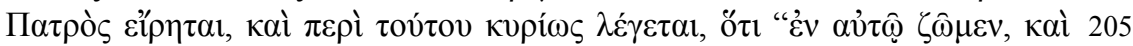

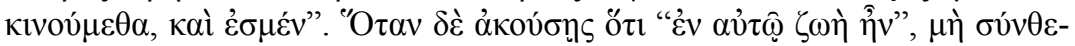

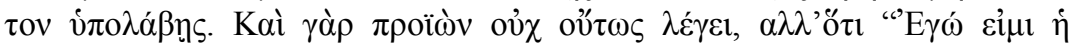

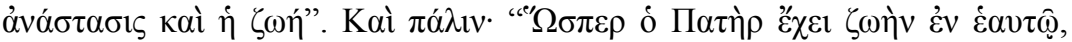

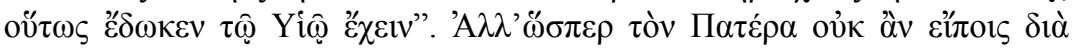

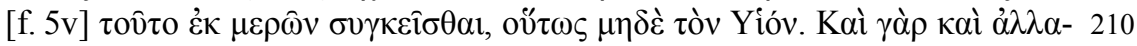

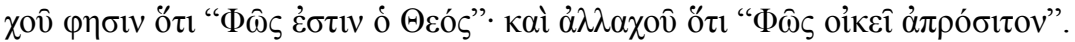

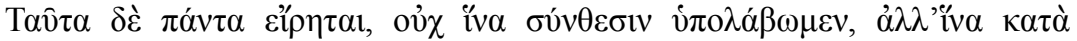

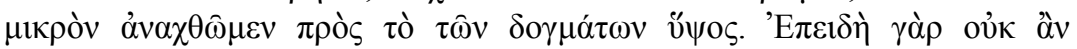

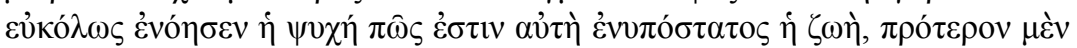

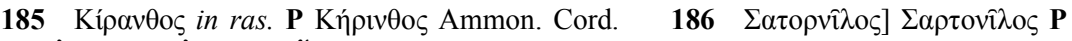

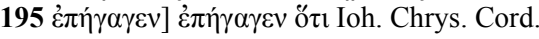

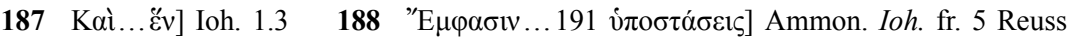

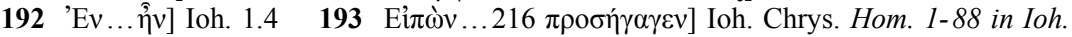

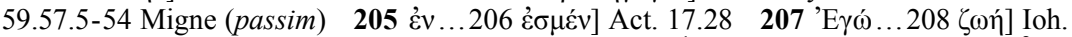

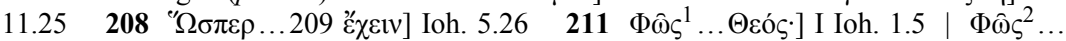

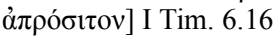


190 Basilides, Nicolaus, Menandrus, Borborianus, Satornilus, Cirinthus. Quocirca et nuptias quidam prohibent et generationem, ut Satornilus et Apostolici.

\section{Et sine ipso factum est nihil}

Ammonii: Emphasim habet sermo quod non solus Filius creavit 195 universa, sed et Pater et Spiritus. Quaecumque enim facit, Pater per Filium in Spiritu Sancto operatur. Et ubi una trium hypostaseon agere dicitur, agunt simul etiam reliquae unius substantiae hypostases.

\section{In ipso vita erat}

Chrysostomi: Cum de creatione dixerit, subdit etiam de providentia 200 sermonem dicens: "In ipso vita erat". Ne quis enim ambigat quo pacto tot tantaque per ipsum facta sint, subiecit: "In ipso vita erat". Integer, inquit, manet nulla ex parte imminutus. Et si mille eiusmodi atque infinitos mundos creare oporteat, idem manet omnibus sufficiens, non ad producendos eos solum, sed etiam post creationem adornandos.

205 Vitae enim nomen hic non creationis solum est, verum etiam providentiae circa durationem. Sermone etiam de resurrectione nobis praestruit faustumque nuncium adfert. Si enim vita nobis adfuit, solutum est imperium mortis; si lux affulsit, non amplius est locus tenebris; si vita est, permanet in perpetuum et mors eam superare non potest. Quocirca

210 quod de Patre dictum est, etiam de hoc proprie dicitur quia "in ipso vivimus, movemus et sumus". Cum atque audieris quod "in ipso vita erat", ne compositum suspiceris. Progrediens enim non ita dicet, sed quia "Ego sum resurrectio et vita". Et rursum: "Quemadmodum Pater habet vitam in se, ita dedit Filio habere". Atqui quemadmodum Patrem

215 non ideo dices ex partibus compositum, ita nec Filium. Nam et alibi ait quia "Deus lux est"; et alibi quia "Lucem habitat inaccessibilem". Haec autem omnia dicta sunt, non ut compositione suspicemus, sed ut paulatim ad dogmatum altitudinem evehamus. Cum enim non facile intelle-

190 Ar ante Menandrus del. ut vid. | Cirinthus] cf. $n .14196$ hypostaseon] hypostasewn V 197 dicitur ex dicatur corr. ut vid. 


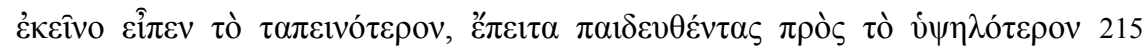

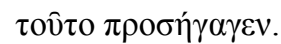

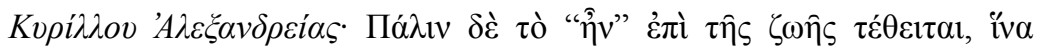

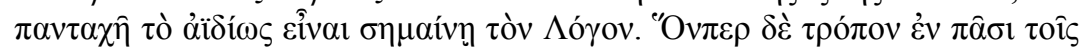

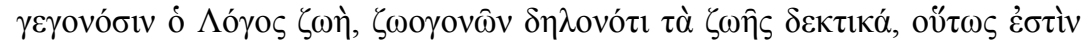

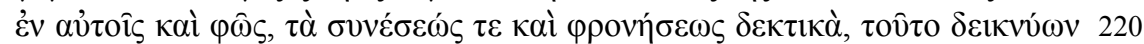

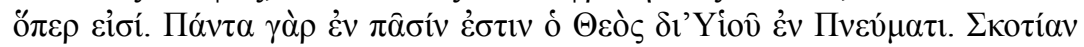

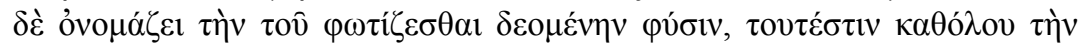
$\gamma \varepsilon v \eta \tau \eta \dot{v . ~}$

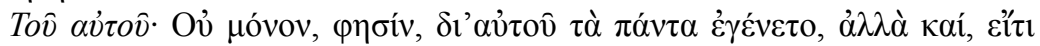

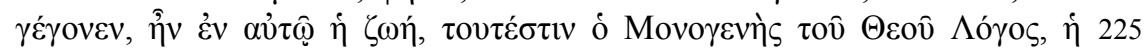

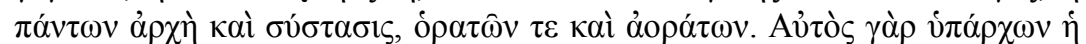

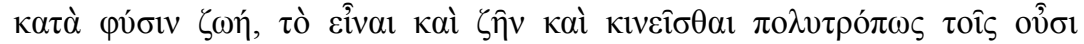

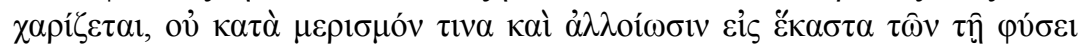

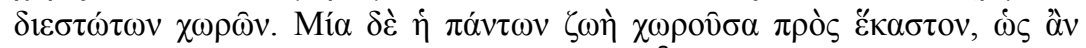

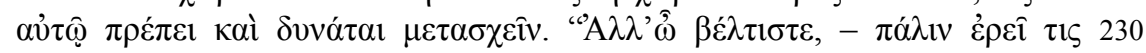

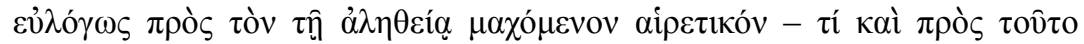

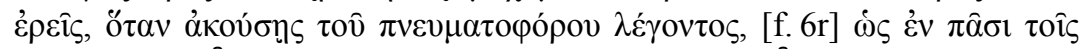

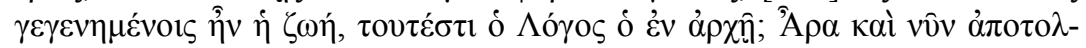

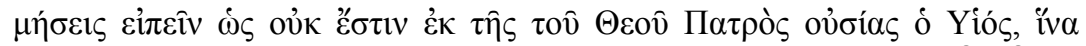

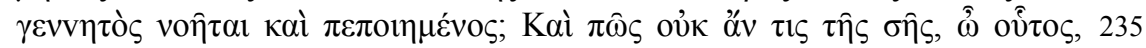

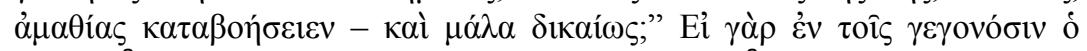

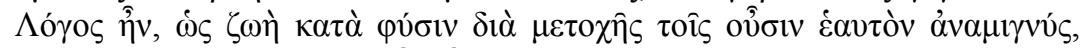

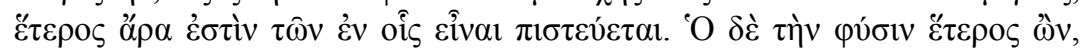

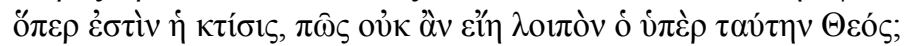

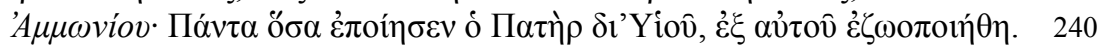

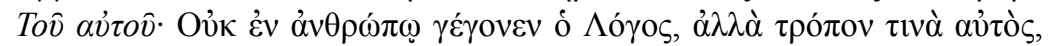

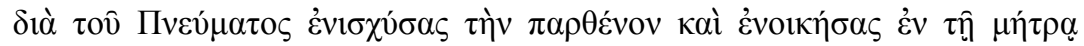

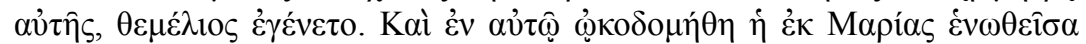

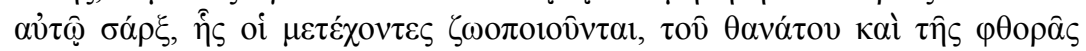

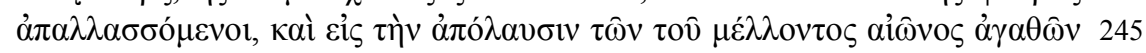

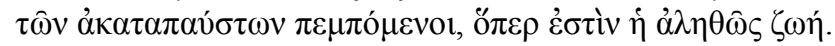

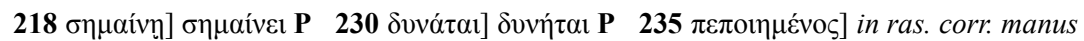

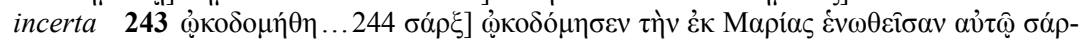
$\kappa \alpha$ Ammon. Cord.

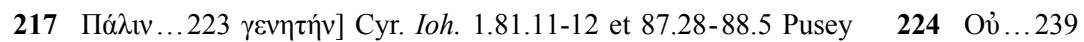

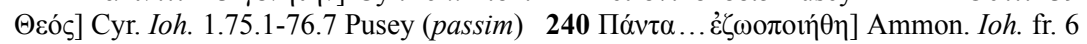

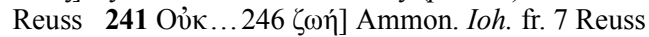


xerit anima quo pacto sit ipsa inexistens vita, primum quidem illud 220 dixit humilius, deinde instructos ad sublimius hoc adduxit.

Cyrilli: Rursum haec particula "erat" ad vitam adiecta est, ut omnino aeternum esse Verbum significet. Ea enim ratione qua in omnibus quae facta sunt est Verbum vita, vivificans nimirum ea quae vitae capacia sunt, ita est in ipsis etiam lux, ea quae intellectus ac prudentiae capacia 225 sunt, id quod sunt esse ostendens. Omnia enim in omnibus est Deus per Filium in Spiritu. Tenebras autem appellat naturam quae illuminatione indiget, hoc est in universum eam quae creata est.

Eiusdem: Non solum, inquit, per ipsum omnia facta sunt, verum etiam si [f. 34v] quid dicimus erat in ipso vita, hoc est Unigenitum Dei

230 Verbum, omnium principium atque fundamentum, visibilium simul et invisibilium. Cum enim ipse naturaliter sit vita, omnibus quae sunt esse et vivere ac moveri multifariam tribuit, non secundum separationem mutationemque in singula natura distantia se conferens. Una vero est omnium vita procedens ad unumquodque, prout cuique convenit ac

235 particeps esse potest. Ac merito quidem aliquis ad haereticum veritati repugnantem dicet: "Quid ad hoc dices, amice, cum audias Ioannem, Spiritu Sancto afflatum, dicentem quod in omnibus creatis erat vita, hoc est Verbum quod in principio? Audebis ne etiamnunc dicere quod non sit ex Dei Patris substantia Filius, ut creatus ac factus censeatur?

240 Quo pacto vero non quis - et quidem iure optimo - tuae inscitiae occlamet?" Si enim in creatis Verbum erat, naturaliter per participationem se ipsum iis quae facta erant commiscens, diversus omnino fuerit ab is in quibus esse creditur. Qui vero diversus natura est ab eo quod est creatura, quo pacto non censendus sit esse is qui supra omnem creatu245 ram est Deus?

Ammonii: Quaecumque fecit Pater per Filium, ex ipso vivificata sunt.

Eiusdem: Non in homine factum est Verbum, sed quodammodo ipsum, per Spiritum corroborans virginem et in utero eius habitans,

250 fundamentum factum est. Et in ipso habitavit caro ex Maria ipsi unita. Cuius qui participes fiunt vivificantur, a morte corruptioneque liberati et ad fruitionem perpetuorum futuri saeculi bonorum traducti, quod revera vita est.

229 dicimus] perperam $\lambda \varepsilon ́ \gamma o \mu \varepsilon v$ pro $\gamma \varepsilon ́ \gamma o v \varepsilon v$ (P 225) lectum videtur 234 cuique ex apte corr. ut vid. 


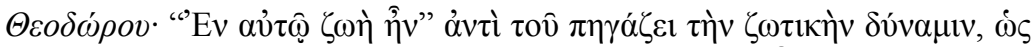

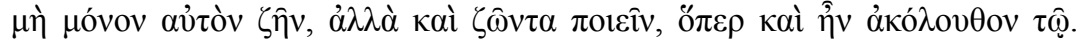

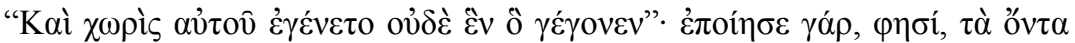

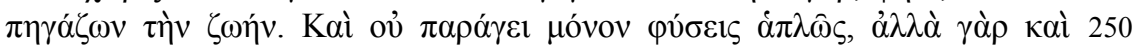

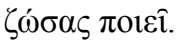

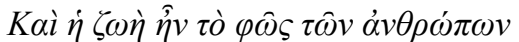

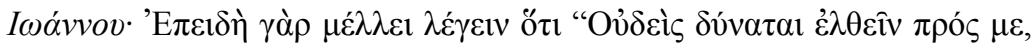

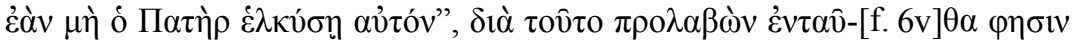

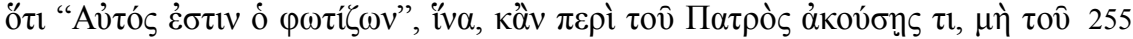

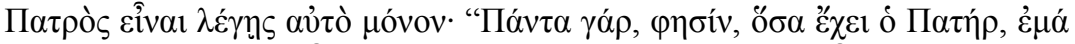

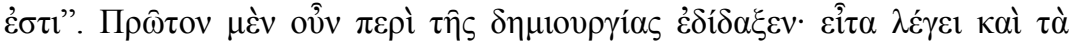

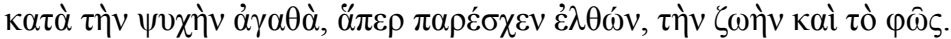

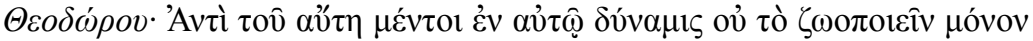

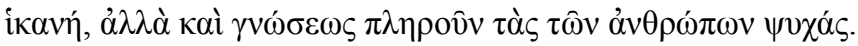

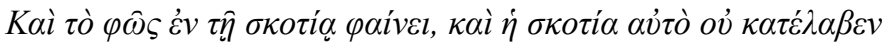

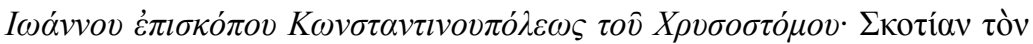

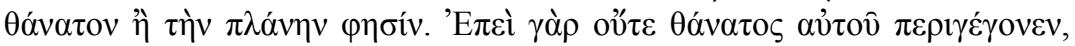

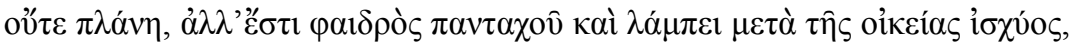

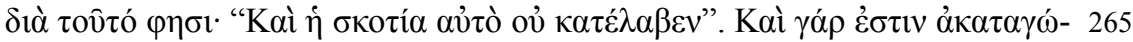

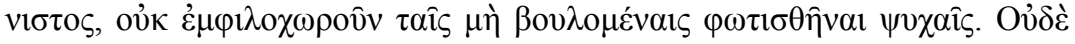

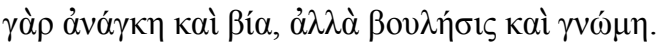

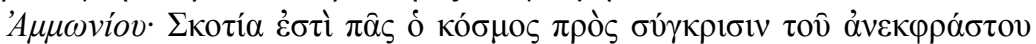

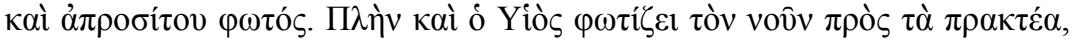

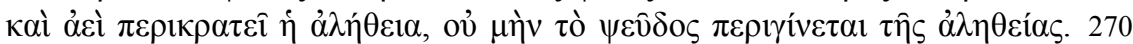

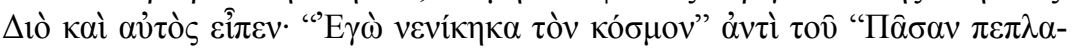

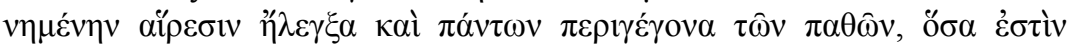

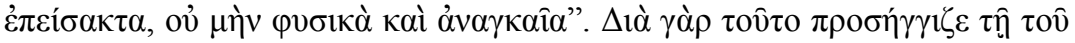

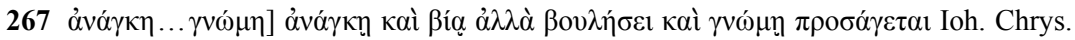

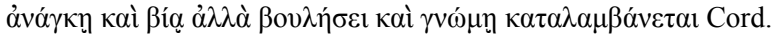

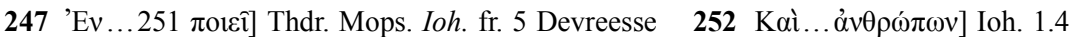

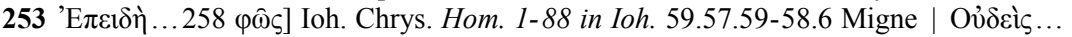

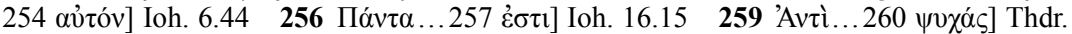

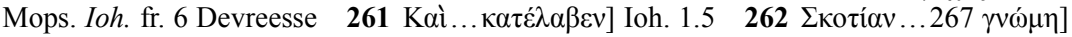

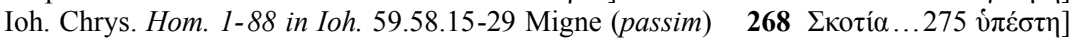
Ammon. Ioh. fr. 10, 1-11 et 14-18 Reuss 
Theodori: "In ipso vita erat" pro scaturit vitalem virtutem, ita ut non 255 solum ipse vivat, sed etiam viventem efficiat, quod quidem consentaneum est illi. "Et sine ipso factum est nihil quod factum est": fecit enim, inquit, omnia scaturiens vitam. Neque solum simpliciter naturas producit, verum etiam vivas efficit.

\section{Et vita erat lux hominum}

260 Chrysostomi: Cum enim dicturus sit quia "Nemo potest venire ad me, nisi Pater trahat eum", idcirco praeveniens: "Hic, inquit, quod ipse sit illuminans", ut, etiamsi de Patre audias aliquid, non illud solum Patris esse dicas: "Omnia enim, inquit, quae habet Pater mea sunt". Primum igitur de Creatione docuit, deinde dicit etiam ea quae ad 265 animam pertinent bona, quae veniens praebuit, vitam nimirum et lucem.

Pro haec quidem erat ipsi virtus, non solum vivificandi potestas, sed etiam replendi scientia humanas animas.

\section{Et lumen in tenebras lucet usque comprehenderunt}

270 Chrysostomi: Tenebrae mortem sive errorem significant. Cum enim neque mors ipsum superarit neque error, sed sit omnino splendidus atque illustris cum proprio suo robore, ideo dixit: "Et tenebrae ipsum non comprehenderunt". Siquidem invictus est, non inhabitans animas quae illuminari nolunt. Neque enim necessitate atque vi, sed voluntate 275 et libera animi sententia agitur.

[f. 35r] Ammonii: Tenebrae sunt totus mundus ad comparationem ineffabilis atque inaccessibilis lucis. Ceterum etiam Filius illuminat mentem ad ea quae facienda sunt, et semper superior evadit veritas, neque vero mendacium superat veritatem. Quam ob rem etiam ipse 280 dixit: "Ego vici mundum", hoc est: "Omnem erroneam haeresim argui, omnesque affectus superavi qui adventitii sunt, non naturales neque necessarii". Idcirco enim appropinquavit Dei Verbi carni, non ut vince-

261 Patrem ante me del. 267 Theodori ante Pro desideratur 268 sci ante replendi del.

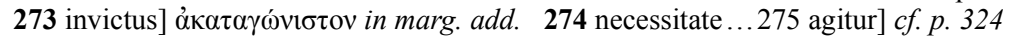




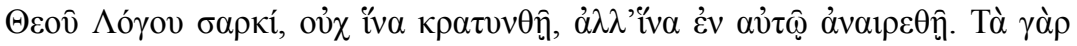

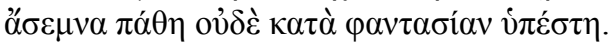

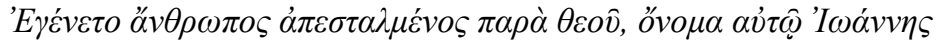

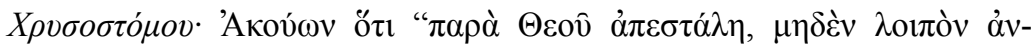

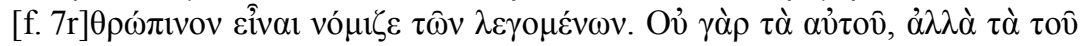

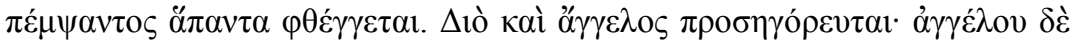

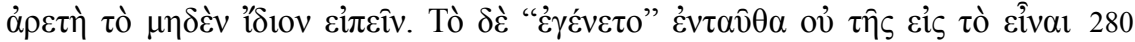

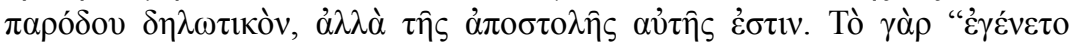

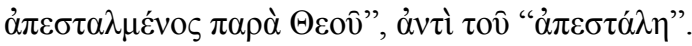

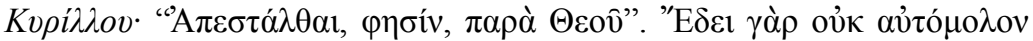

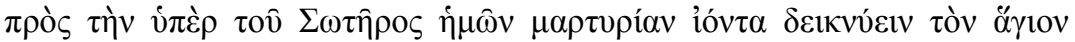

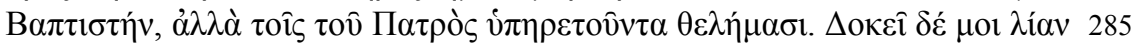

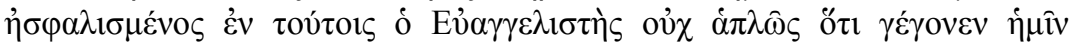

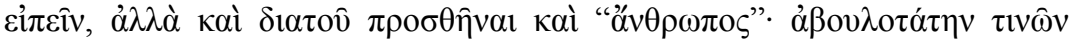

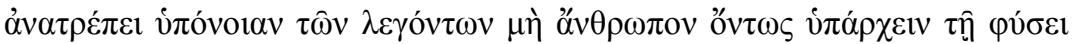

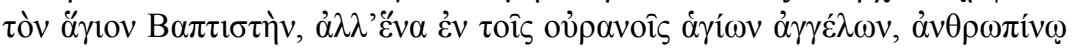

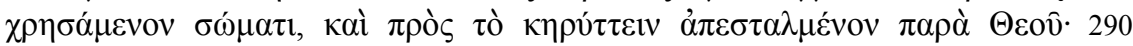

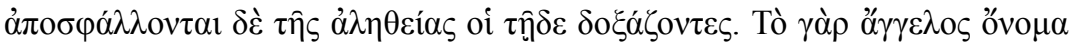

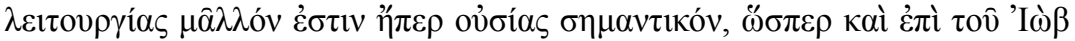

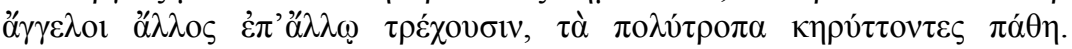

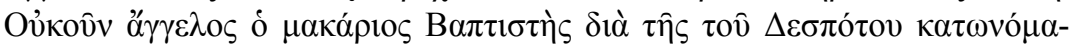

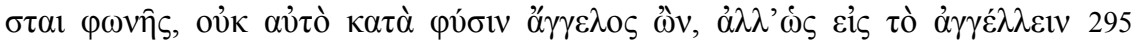

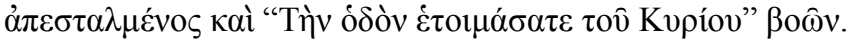

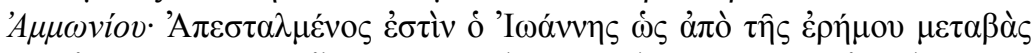

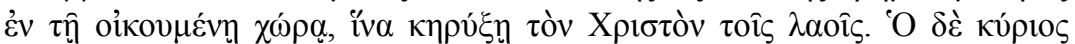

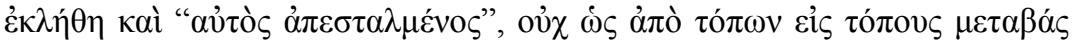

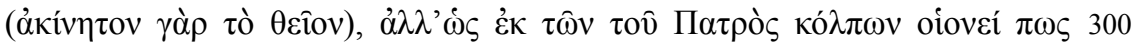

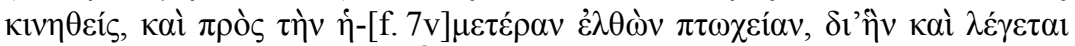

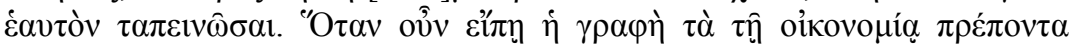

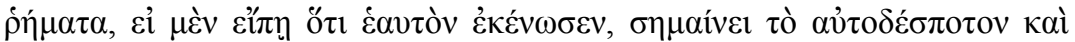

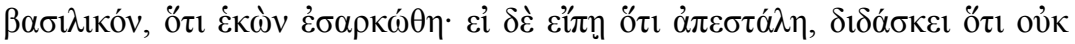

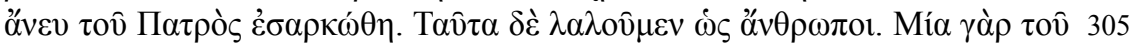

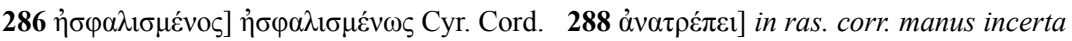

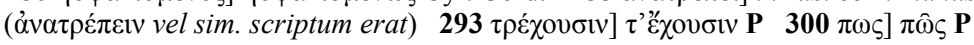

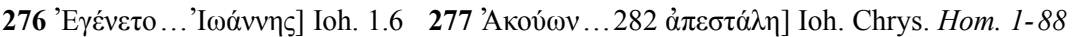

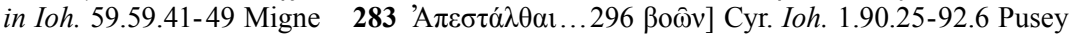

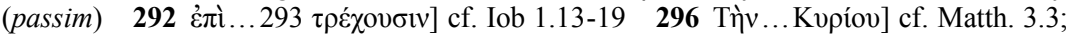

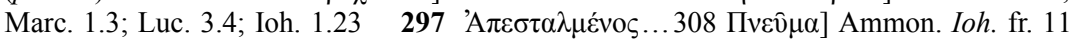

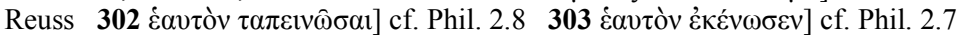


retur, sed ut in ipso tolleretur. Foedi enim affectus ne secundum imaginationem quidem substiterunt.

\section{Fuit homo missus a Deo cui nomen Ioannes}

Chrysostomi: Audiens "missum a Deo", nihil amplius eorum quae dicuntur humanum esse cogita. Neque enim sua, sed eius qui misit omnia loquitur. Qua de causa etiam nuncius appellatus est: nuncii autem munus est nihil proprium dicere. Illud vero quod dicitur "fuit" 290 non significat transitum ad esse, sed ipsius missionis est. Nam "fuit missus a Deo" dictum est pro "mittebatur".

Cyrilli: "Missus est, inquit, a Deo". Oportebat enim ostendere Sanctum Baptistam non ex se suoque instinctu ad testimonium de Salvatore nostro dandum venire, sed Patris voluntati atque iussui servientem.

295 Videtur autem mihi tutissime in his Evangelista non simpliciter dixisse quod fuerit, sed adiecisse "homo", stultam quorundam opinionem subvertens dicentium Sanctum Baptistam non revera esse natura hominem, sed unum ex sanctis angelis qui in coelo degunt humano indutum corpore et ad praedicandum missum esse a Deo: aberrant autem a 300 veritate qui ita sentiunt. Angeli enim nomen ministerium plus quam substantiam significat. Sic enim alium super alium ad Beatum Iob angelos cucurrisse legimus, varias calamitates quae imminebant nunciantes. Angelus itaque Beatus Baptista per Domini vocem appellatus est, non quod ipse ex sua natura angelus esset, sed tanquam ad 305 nunciandum missus et clamans: "Praeparate viam Domini".

Ammonii: Missus est Ioannes ut e deserto transiens in locum habitatum, ut praedicet Christum populis. Dominus autem etiam dictus est "missus" non tanquam de loco in locum transiens (immobilis enim est divinitas), sed veluti ex sinu Patris quodammodo motus et ad nostram 310 inopiam demissus, propter quam etiam dicitur se ipsum humiliasse. Cum igitur dicat scriptura verba divino consilio sive oeconomiae convenientia, si dixerit quod se ipsum exinanivit, significat dominicam

283 ipso supra lineam add. 295 tutissime] cf. $n .14 \mathbf{3 0 2}$ cucurrisse] $c f . n .14$

Humanistica Lovaniensia 68.2 (2019), 317-359 


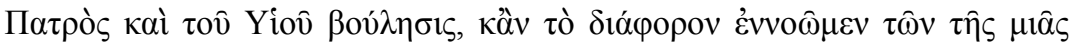

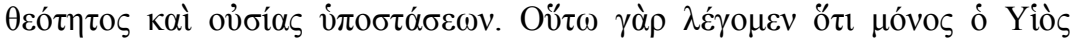

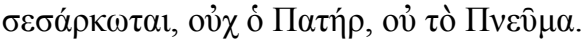

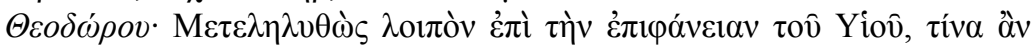

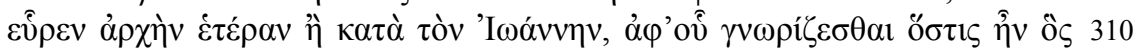

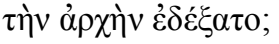

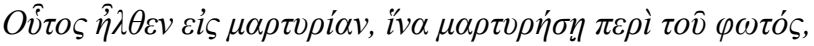

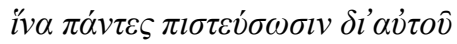

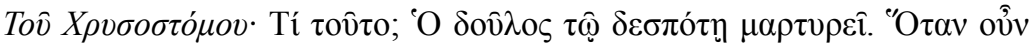

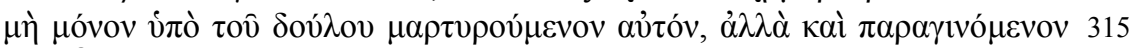

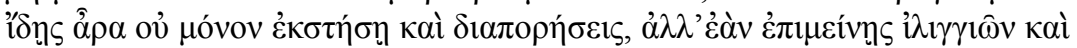

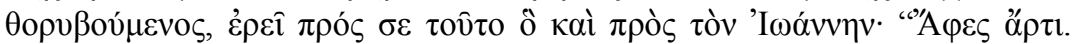

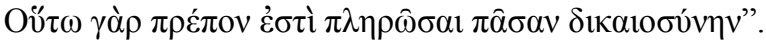

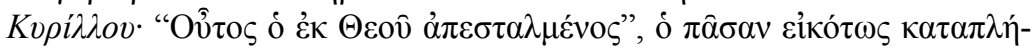

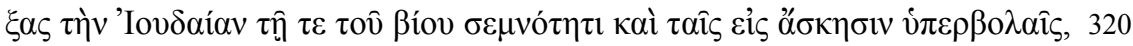

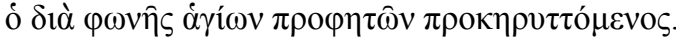

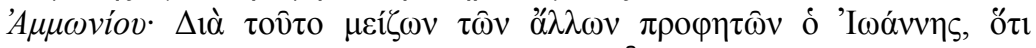

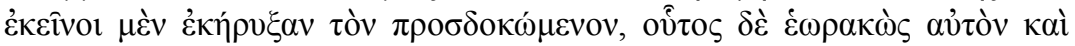

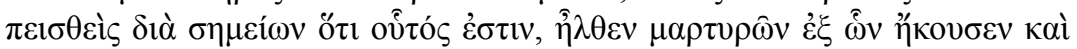
$\varepsilon i \delta \varepsilon v$.

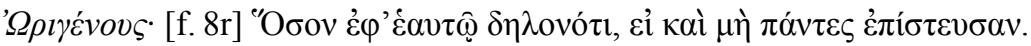

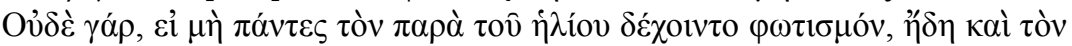

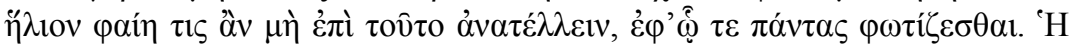

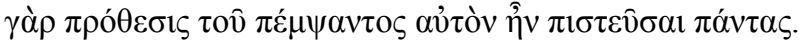

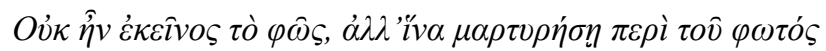

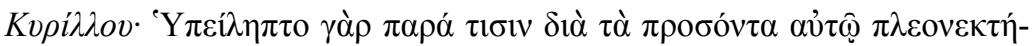

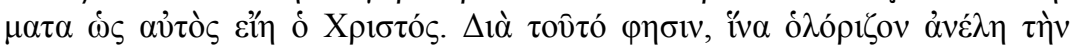

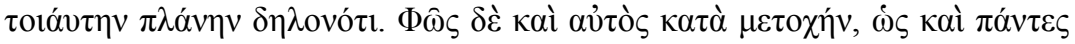
oi ärior.

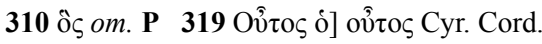

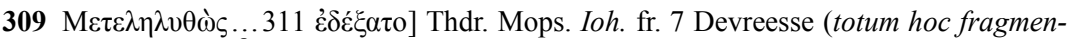

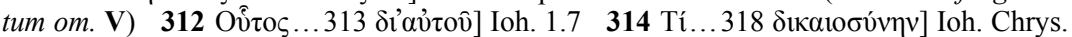

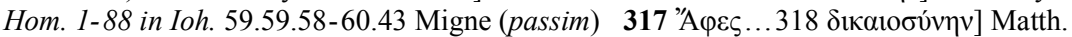

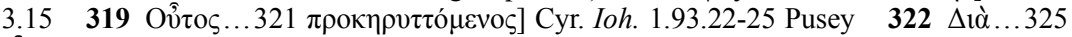

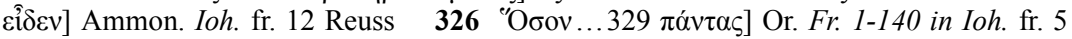

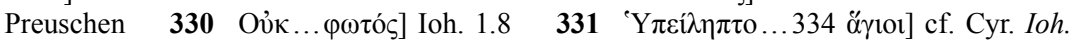
1.94.14-95.15 Pusey 
suam ac regiam dignitatem, quia volens incarnatus est; si autem dixerit quod missus sit, docet quod non absque Patre incarnatus sit. Haec vero 315 loquimur ut homines. Una enim est Patris et Filii voluntas, etiamsi differentiam intelligamus unius deitatis atque essentiae hypostaseon. Ita enim dicimus quod solus Filius incarnatus sit, non Pater neque Filius.

\section{Hic venit etc. usque per ipsum}

320 Chrysostomi: Quid hoc? Servus domino testimonium dat. Quando igitur non solum a servo testificatum ipsum, verum etiam parentem videris, non solum stupebis atque ambiges, sed, si permanseris caligans ac turbatus, dicet tibi idem quod ad Ioannem: "Desine modo. Ita enim oportet impleri omnem iustitiam".

325 Cyrilli: Hic ex Deo missus, qui totam merito Iudaeam in sui admirationem traxit pietate vitae atque excellentia operum, qui per vocem sanctorum prophetarum praedictus est.

[f. 35v] Ammonii: Idcirco maior est aliis prophetis Ioannes, quia illi quidem praedicarunt eum qui expectabatur, hic autem, cum eum vidis-

330 set et credidisset per signa quod hic esset, venit testificans ex iis quae audivit et vidit.

Origenis: Quoad in ipso erat, etiamsi non omnes crediderint. Neque enim, si non omnes lucem solis excipiant, idcirco dicat quis solem non ideo oriri, ut omnes illuminet. Intentio enim mittentis ipsum erat ut 335 omnes crederent.

Non erat ille etc. usque de lumine

Cyrilli: Existimabant enim nonnulli ob eximiam ipsius praestantiam ipsum esse Christum. Ideo id inquit ut radicitus hunc errorem evellat. Lux autem etiam ipse est iuxta participationem, quemadmodum et 340 omnes sancti.

316 hypostaseon] hypostase $\omega n$ V 318 Filius] perperam Filius pro Spiritus scriptum est 333 crediderint ante lucem del. 


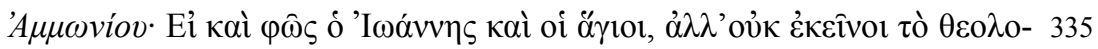

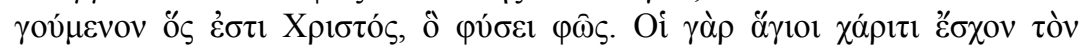

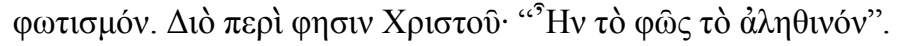

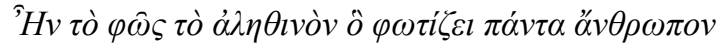

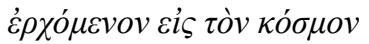

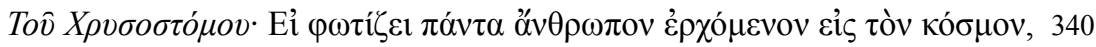

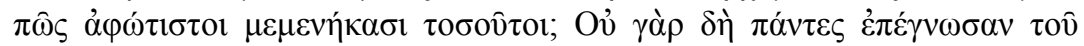

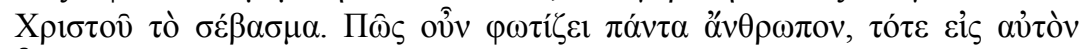

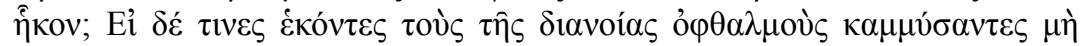

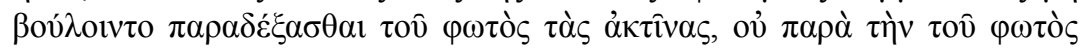

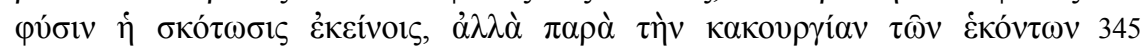

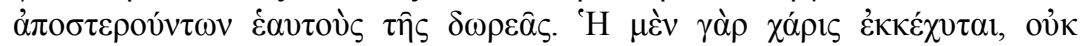

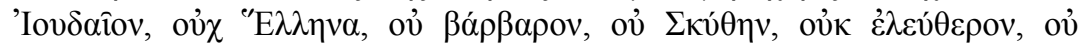

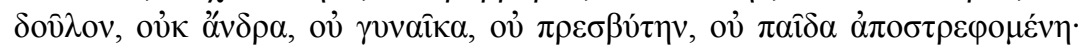

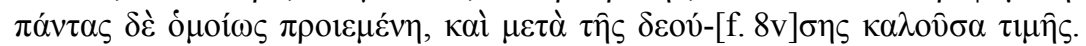

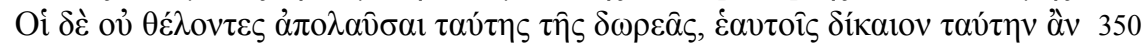

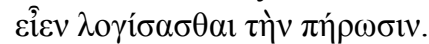

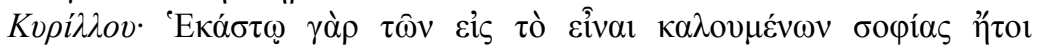

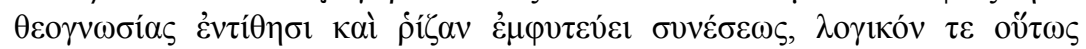

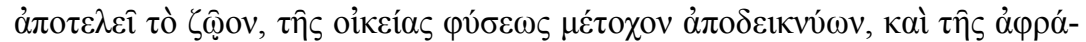

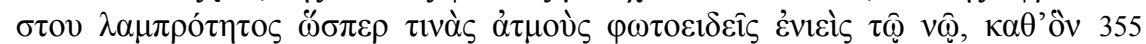

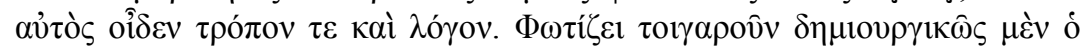

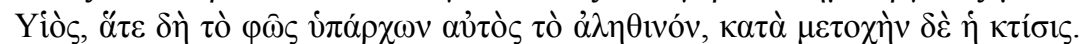

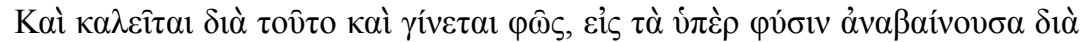

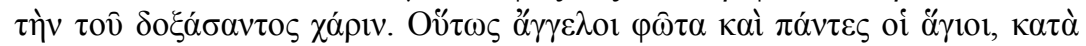

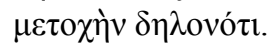

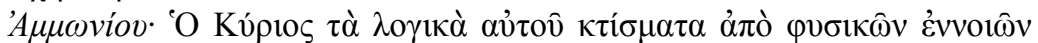

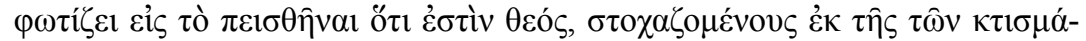

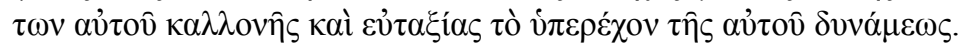

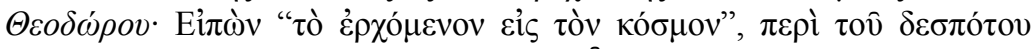
X

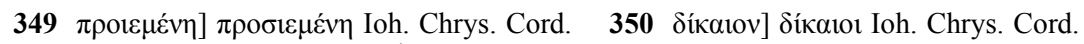

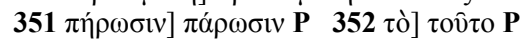

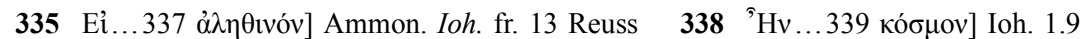

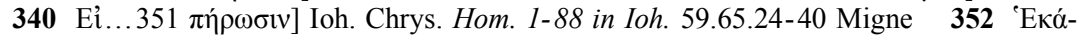

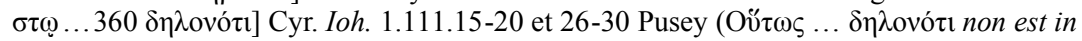

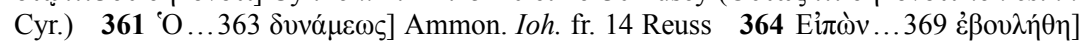
Thdr. Mops. Ioh. fr. 9.1-12 Devreesse 
Ammonii: Etiamsi lux sit Ioannes et sancti, non tamen illi ea quae de deo dicitur, quae est Christus, qui naturaliter lux est. Sancti enim per gratiam habuerunt illuminationem. Idcirco ait de Christo: "Erat lux vera".

Chrysostomi: Si illuminat omnem hominem venientem in mundum, quo pacto tot relicti sunt luminis expertes? Neque enim omnes cognoverunt Christi cultum. Quo pacto igitur illuminat omnem hominem venientem in mundum? Si vero nonnulli sua sponte mentis oculos 350 comprimentes lucis radios excipere nolunt, non ex lucis natura ea occaecatio sive caligo ipsis obvenit, sed ex sua ipsorum nequitia, qui se ipsos eius beneficentia privant. Gratia enim effusa est non Iudeum, non Graecum, non Barbarum, non Scytham, non liberum, non servum, non virum, non mulierem, non senem, non puerum exludens, sed omnes ex 355 aequo adgrediens atque eo quo oportet cum gloria vocans. Qui vero eo dono frui nolunt, merito sua ipsorum occaecatio imputari potest.

Cyrilli: Unicuique eorum qui ad esse vocati sunt, Deus sapientiae sive cognitionis Dei radicem inserit atque ita rationale animal efficit, propriae naturae particeps declarans, et ineffabilis splendoris veluti 360 radios quosdam menti, eo quo ipse novit modo ac ratione, immittens. Illuminat igitur creative Filius, utpote qui vera lux est, per participationem vero creatura. Et vocatur ideo et est lux, ad supernaturalia conscendens per glorificantis gratiam. Sic angeli etiam et omnes sancti sunt lumina, per participationem nimirum.

365 Ammonii: Deus rationales suas creaturas ex naturalibus notionibus illuminat ad credendum quod sit Deus, colligentes ex creaturarum pulchritudine atque ordine excellentem ipsius potentiam.

Theodori: Cum dixisset "venientem in mundum", de domino Christo pulchre huic subiecit: "In mundo erat", ut ostendederet quod "venien-

361 creative] $\delta \eta \mu 10 u \rho \gamma \hat{\omega}$ s in marg. add. 


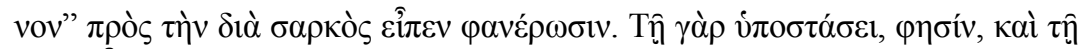

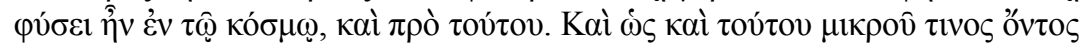

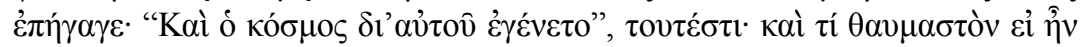

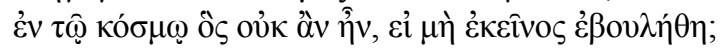

\section{'Ev $\tau \hat{\omega} \kappa o ́ \sigma \mu \omega \hat{\eta} v$}

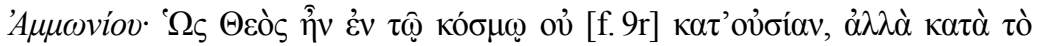

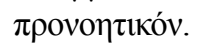

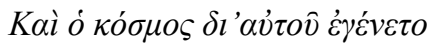

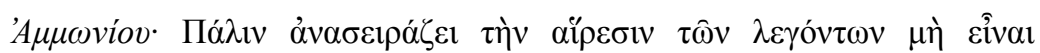

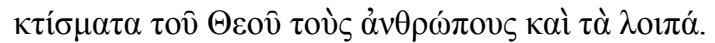

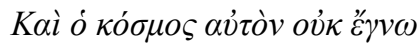

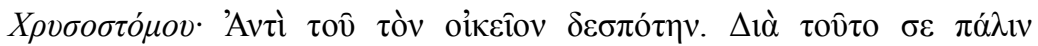

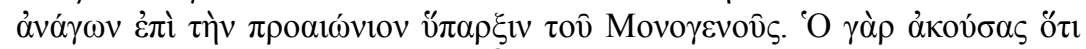

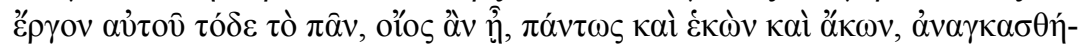

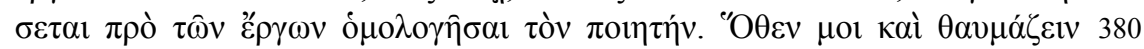

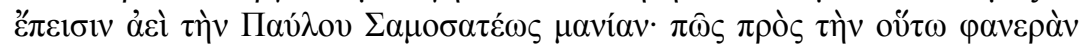

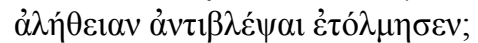

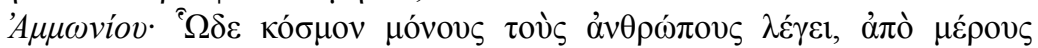

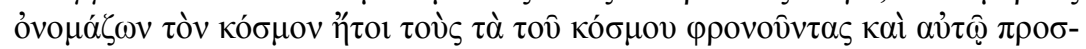

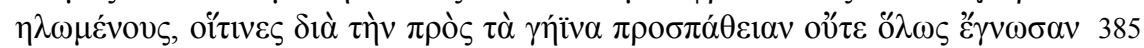

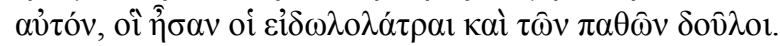

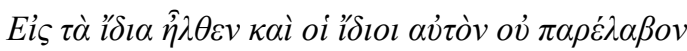

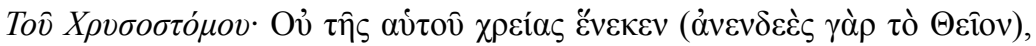

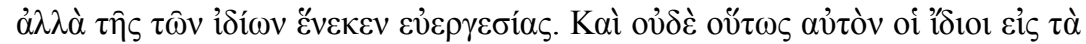

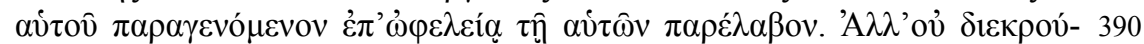

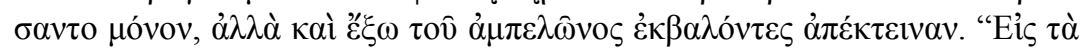

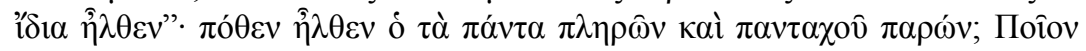

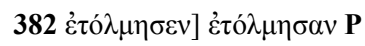

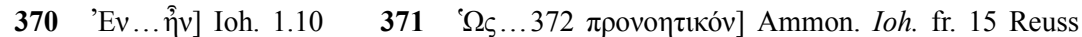

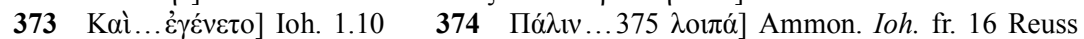

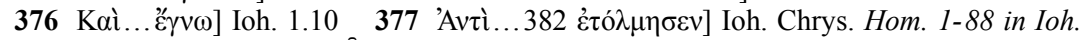
59.65.46-54 Migne $383{ }^{\circledR} \Omega \delta \varepsilon \ldots 386 \delta$ ov̂ $\lambda$ ol] Ammon. Ioh. fr. 17 Reuss 387 Eís...

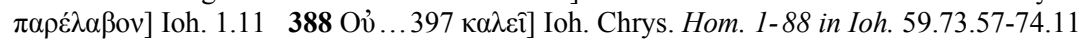

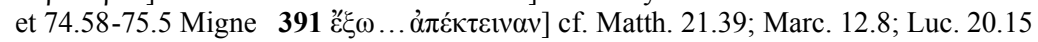


370 tem" ad manifestationem per carnem dixerit. Hypostasi enim, inquit, et natura in mundo erat, etiam ante hunc. Ac veluti etiam hoc parvum aliquid esset, adiecit: "Et mundus per ipsum factus est", hoc est: quid mirum si erat in mundo qui ne extitisset quidem, nisi ille voluisset?

\section{In mundo erat}

375 Ammonii: Tanquam Deus erat in mundo non secundum substantiam, sed secundum providentiam.

\section{Et mundus per ipsum factum est}

Ammonii: Rursum convellit haeresim dicentium homines et reliqua non esse creatura Dei.

\section{Et mundus ipsum non cognovit}

Chrysostomi: Pro proprium dominum. Atqui per hoc rursus [f. 36r] deducit ad praeeternam Unigeniti existentiam. Qui enim audierit quod hoc universum sit opus ipsius, quicumque is fuerit, omnino volens nolens, cogetur ante opera factum ipsum confiteri. Quo fit ut summo385 pere semper admirer Pauli Samosatensis insaniam: quo pacto enim ad eo manifeste veritati repugnare ausus fuit?

Ammonii: Hic mundum solos homines dicit, ex parte appellans mundum, vel eos qui mundana cogitant eique affixi sunt, qui quidem ob affectum ad terrena neque omnino cognoverunt eum, idolatrae et 390 servi affectuum.

\section{In propria venit et sui eum non receperunt}

Chrysostomi: Non suae ipsius necessitatis causa (nullius enim indiget Deus), sed iuvandi suos gratia. At neque sic quidem sui ipsum in sua venientem ad eos iurandos receperunt. Sed non repulerunt 395 solum, verum etiam e vinea eiectum interfecerunt. "In propria venit": unde venit qui cuncta replet et ubique praesens est? Quem locum sua

376 proprietatem ante providentiam del. 381 Pro ex quasi dicat corr. 382 Dei ante Unigeniti del. 395 vinea] i ex e ut vid. corr. 


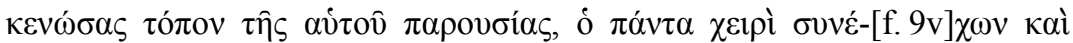

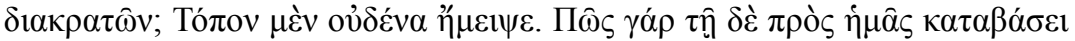

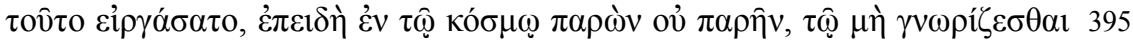

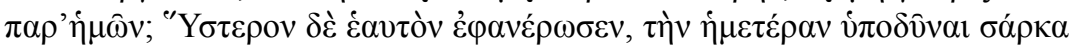

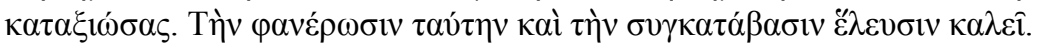

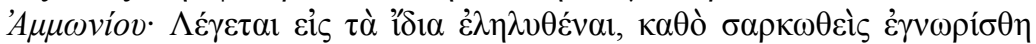

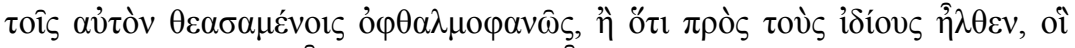

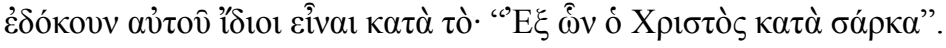

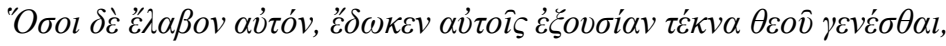

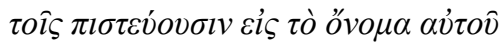

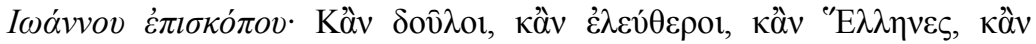

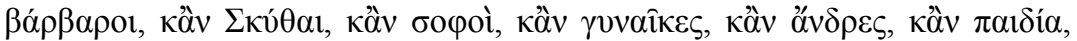

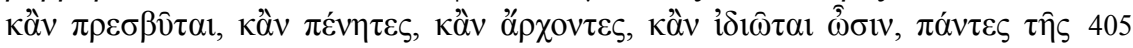

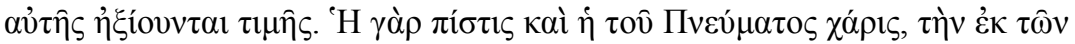

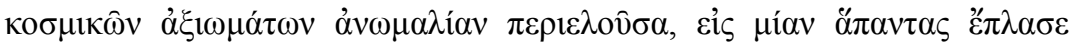

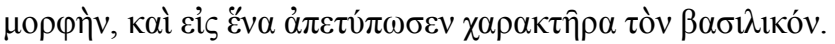

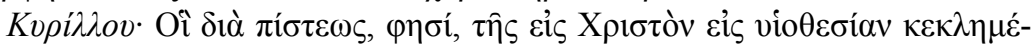

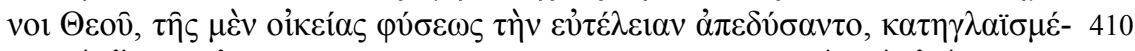

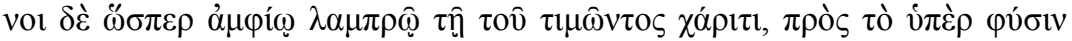

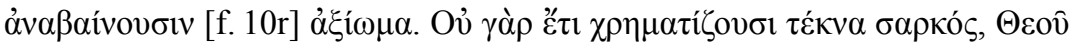

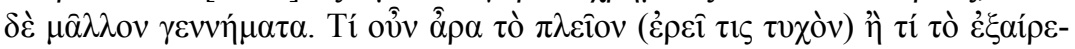

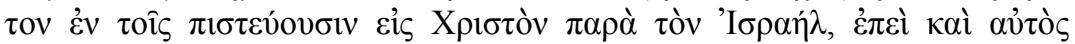

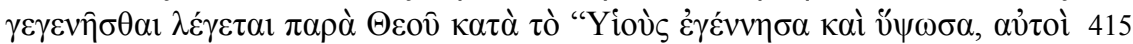

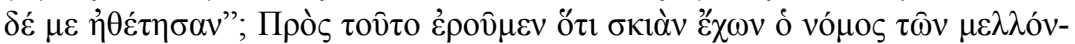

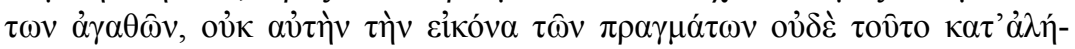

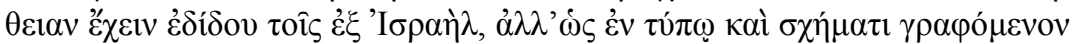

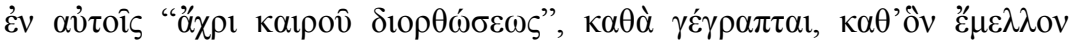

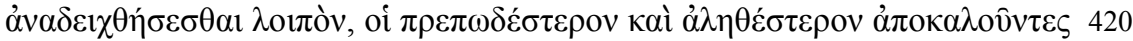

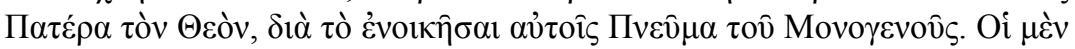

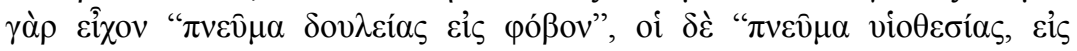

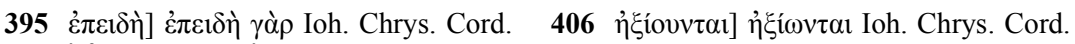

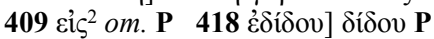

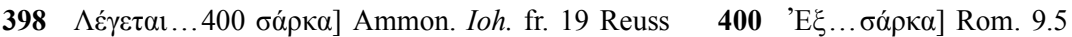

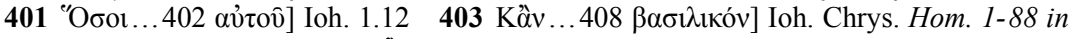

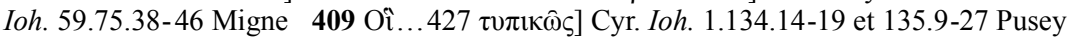

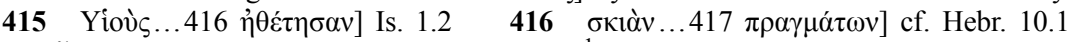

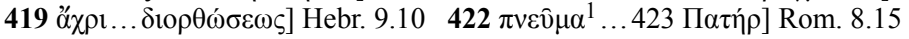


praesentia vacuavit, qui omnia manu continet atque conservat? Nullum quidem locum mutavit. Quo pacto enim suo ad nos descensu id operatus est, quandoquidem in mundo cum esset non aderat ideo quod a 400 nobis cognosceretur? Postmodum vero manifestavit se ipsum, carnem nostram subire dignatus. Hanc manifestationem et descensum vocavit adventum.

Ammonii: Dicitur in propria venisse, quia incarnatus cognitus est iis qui ipsum oculis suis viderunt, vel quia ad proprios venit qui videban405 tur proprii ipsius esse, iuxta id: "Ex quibus Christus secundum carnem".

\section{Quotquot autem usque nomen eius}

Chrysostomi: Sive servi, sive liberi, sive Graeci, sive barbari, sive Scythes, sive sapientes, sive mulieres, sive viri, sive pueri, sive senes, 410 sive pauperes, sive principes, sive idiotae sint, omnes eodem dignati sunt honore. Fides enim et Spiritus gratia, mundanarum dignitatum inaequalitatem e medio tollens, in unam omnes formam formavit unaque figura sive charactere regio insignivit.

Cyrilli: Qui fide Christi, inquit, in adoptione filiorum vocati sunt, 415 humilitatem naturae suae deposuerunt et, veluti splendida veste illustrati eius qui ipsos honore efficere voluit beneficio, ad dignitatem natura sua maiorem conscenderunt. Neque enim amplius vocantur filii carnis, sed potius filii Dei. Sed quid maius (dicet quispiam) aut quid praecipuum credentibus in Christum tributum est ultra quam Israëli,

420 siquidem etiam ipse ex Deo natus dicitur iuxta illud: "Filios genui et exaltavit, ipsi autem spernerunt me"? Ad hoc dicemus quod lex, umbram habens futurorum bonorum, non eandem speciem rerum neque idem revera Israëlitis habere concessit, sed veluti in typo atque figura descriptum "usque ad instaurationem temporis", sicut scriptum est, quo 425 emersuri erant qui convenientius atque verius Deum Patrem appellarent, ob inhabitantem ipsis Spiritum Unigeniti. Illi enim habuerunt "Spiritum servitutis in timorem"; hi vero "Spiritum adoptionis

422 speciem] éıkóva in marg. add. 


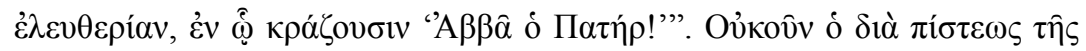

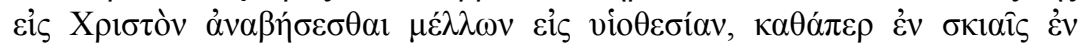

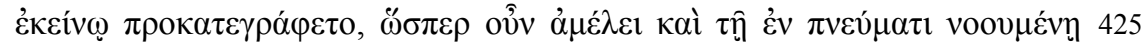

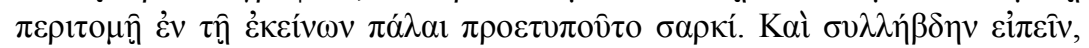

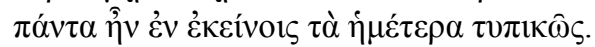

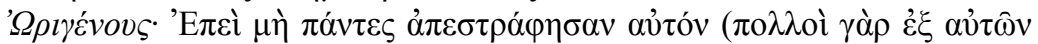

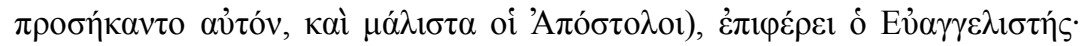

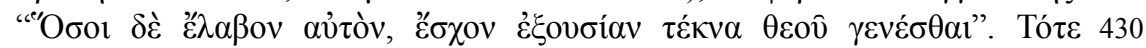

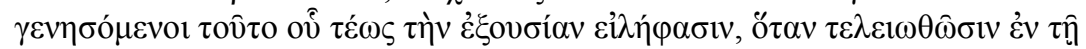

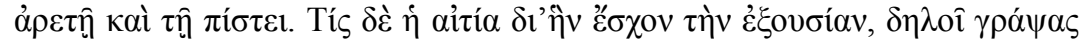

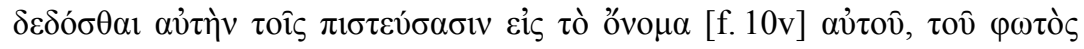
$\delta \eta \lambda$ ovótı.

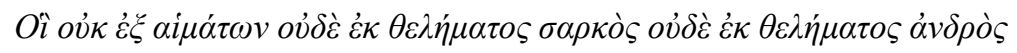

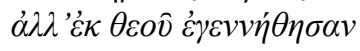

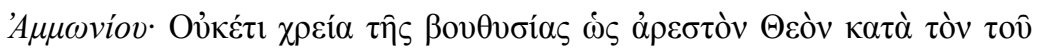

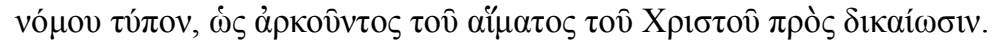

428 'E

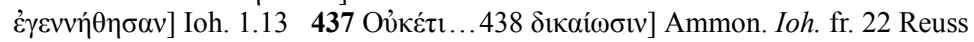


filiorum" in libertatem "in quo clamant: 'Abba, Pater!"”. Populus itaque qui per fidem in Christum oriturus erat in illo tanquam in umbra 430 descriptus fuit, quemadmodum etiam circumcisio in Spiritu olim in illo pro carne praefigurata fuit. Atque, ut breviter dicam, omnia nostra in illis typice adumbrata fuerunt.

Origenis: Quandoquidem non omnes ipsum reicerunt (multi enim [f. 36v] ex eis eum admiserunt, ac precipue Apostoli), infert Evangeli435 sta: "Quotquot autem receperunt eum, dedit eis potestatem filios Dei fieri". Tunc futuri id cuius potestatem acceperunt, quando perfecti fuerint in virtute et fide. Quaenam vero causa sit propter quam habuerunt potestatem, declarat scribens datam eam credentibus in nome ipsius, lucis nimirum.

Qui non ex sanguinibus usque ex Deo nati sunt

Ammonii: Non amplius est opus boum sacrificio ut Deum placatum habeamus iuxta legis typum, utpote cum sufficiat sanguis Christi ad iustificationem.

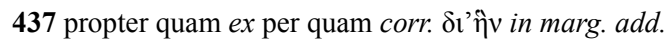

